\title{
SOEP
}

SOEPpapers

SOEPpapers
on Multidisciplinary Panel Data Research
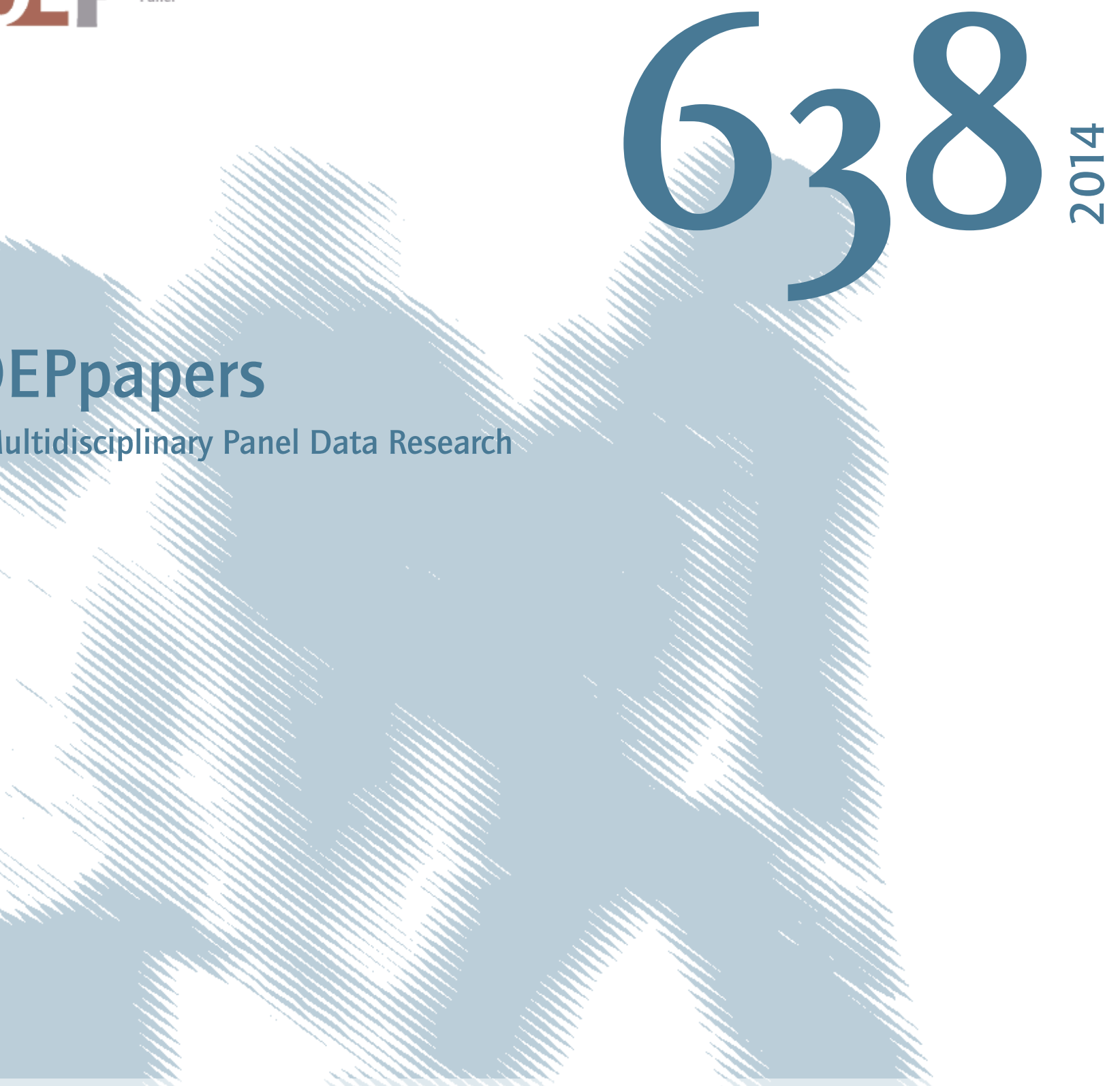

\section{Reference-Dependent Effects of Unemployment on Mental Well-Being}




\section{SOEPpapers on Multidisciplinary Panel Data Research}

at DIW Berlin

This series presents research findings based either directly on data from the German SocioEconomic Panel Study (SOEP) or using SOEP data as part of an internationally comparable data set (e.g. CNEF, ECHP, LIS, LWS, CHER/PACO). SOEP is a truly multidisciplinary household panel study covering a wide range of social and behavioral sciences: economics, sociology, psychology, survey methodology, econometrics and applied statistics, educational science, political science, public health, behavioral genetics, demography, geography, and sport science.

The decision to publish a submission in SOEPpapers is made by a board of editors chosen by the DIW Berlin to represent the wide range of disciplines covered by SOEP. There is no external referee process and papers are either accepted or rejected without revision. Papers appear in this series as works in progress and may also appear elsewhere. They often represent preliminary studies and are circulated to encourage discussion. Citation of such a paper should account for its provisional character. A revised version may be requested from the author directly.

Any opinions expressed in this series are those of the author(s) and not those of DIW Berlin. Research disseminated by DIW Berlin may include views on public policy issues, but the institute itself takes no institutional policy positions.

The SOEPpapers are available at

http://www.diw.de/soeppapers

\section{Editors:}

Jürgen Schupp (Sociology)

Gert G. Wagner (Social Sciences, Vice Dean DIW Graduate Center)

Conchita D'Ambrosio (Public Economics)

Denis Gerstorf (Psychology, DIW Research Director)

Elke Holst (Gender Studies, DIW Research Director)

Frauke Kreuter (Survey Methodology, DIW Research Professor)

Martin Kroh (Political Science and Survey Methodology)

Frieder R. Lang (Psychology, DIW Research Professor)

Henning Lohmann (Sociology, DIW Research Professor)

Jörg-Peter Schräpler (Survey Methodology, DIW Research Professor)

Thomas Siedler (Empirical Economics)

C. Katharina Spieß (Empirical Economics and Educational Science)

ISSN: 1864-6689 (online)

German Socio-Economic Panel Study (SOEP)

DIW Berlin

Mohrenstrasse 58

10117 Berlin, Germany

Contact: Uta Rahmann | soeppapers@diw.de 


\title{
Reference-Dependent Effects of Unemployment on Mental Well-Being
}

\author{
Martina Grunow*
}

24th February 2014

\begin{abstract}
This paper provides an empirical analysis of reference-dependent effects of unemployment on mental well-being. We show that the negative effect of unemployment on mental well-being depends on expectations about the future employment status.

Several contributions to the literature have shown that the perception of the individual employment status depends on the surrounding unemployment rate. We argue that expectations are a possible link between unemployment rates and the individual employment status regarding changes in mental well-being. Theoretical foundation comes from models for reference-dependent preferences with endogenous reference points. We provide a simple theoretical model to motivate and structure the empirical analysis. Using data from the German Socio-Economic Panel, we estimate a pairwise interacted model for employment status and expectations over two time periods. Life satisfaction is used as a proxy for mental well-being. To identify a causal effect of unemployment, expectations and their interactions on mental wellbeing, the analysis relies on fixed effects and exogenous entries into unemployment due to plant closures. We confirm the standard result that unemployment has a
\end{abstract}

*University of Augsburg, Department of Economics, Universitätsstr. 16, 86159 Augsburg, Germany, Email: martina.grunow@wiwi.uni-augsburg.de, Phone: +49-821-598-4210, Fax: +49-821-598-4232. I thank the participants of several conferences and seminars for comments and suggestions that greatly improved the paper. Financial support from the Research Center Global Business Management at the University of Augsburg is gratefully acknowledged. The views expressed are those of the author alone. 
negative effect on mental well-being. Furthermore, the results deliver empirical evidence for reference-dependent effects of unemployment on mental well-being. We find that becoming unemployed unexpectedly is more severe as if the unemployment was expected. Therefore, this paper contributes to the understanding of how mental well-being is affected by unemployment and delivers empirical support for the theoretical models of reference-dependent preference wit endogenous reference points determined by expectations.

Keywords: Subjective Well-Being, Unemployment, Reference-Dependence, Reference Points.

JEL classification numbers: C23, D03, D84, I10, I18, J01, J60. 


\section{Introduction}

The relationship of unemployment and health has been amongst others discussed in a series of papers by Ruhm (e.g. 2000, 2003, 2005) who found that unemployment rates are negatively correlated with mortality rates, health care utilization and chronic conditions. Interpreting mortality rates as a proxy for health he concludes that with decreasing macro-economic circumstances health increases. He reasons that people have more time for health increasing activities during recessions but tend to more risky health behavior during economic upswings (smoking, drinking, etc.). When he analyzes the effect of unemployment rates on case-specific mortality rates and specific chronic diseases he finds that only the variation in suicides and mental illness to be procyclical in macro-economic conditions, i.e. suicide rates and the number of mental health problems increase with unemployment rates. He concludes that mental health and mental well-being behave in sharp contrast to physical well-being (Ruhm 2003, p. 655). Therefore, the relationship between mental well-being and economic conditions should be analyzed separately from physical health conditions.

The number of reported mental health problems is steadily increasing in recent years. Health care expenditures caused by mental illnesses are increasing above average compared to expenditures for physical health problems (Statistisches Bundesamt, 2010). As it seems that mental well-being is differently affected by (macro-) economic circumstances than physical health it is of particular importance for health economists to understand what determines mental well-being.

On the individual level Clark and Oswald (1994) established the general result that subjective well-being is negatively affected from unemployment. Winkelmann and Winkelmann (1998) disentangled the negative effect of unemployment on life satisfaction into a pecuniary and a non-pecuniary effect. The non-pecuniary effect is the psychological burden of unemployment that arises in addition to the loss of income that characterizes

the economic burden of unemployment. They found the non-pecuniary effect to be much larger than the effect that stems from the associated loss of income due to unemployment.

Other studies (e.g. Clark et al. 2009) find that the negative effect of unemployment on mental well-being itself is related to the regional unemployment rate. This result is 
usually discussed in the context of social norms. The general findings state that being unemployed in a high unemployment rate region has a smaller negative effect on mental well-being as if the unemployed would live in a region with a low unemployment rate. In high unemployment rate regions being unemployed means to be conform to the social norm of unemployment. The results suggest that not deviating from the social norm lowers the psychological burden of unemployment. In contrast, Vatter (2012) found that subjective well-being in East Germany where unemployment rates are considerably higher than in West Germany is more affected when it comes to unemployment. He argues that lower job prospects in high unemployment rate regions increase the negative effect from unemployment. Clark et al. (2010) and Knabe and Rätzel (2011) provide empirical evidence for this relationship and show that current negative expectations about becoming re-employed in the future additionally reduce subjective well-being among the unemployed. These studies agree in that the negative effect from unemployment on mental well-being is heterogenous among individuals. Furthermore, the size of the negative effect depends on unemployment rates and future job prospects. But from the economic literature the mechanism how these components affect the perception of the employment status remains unclear.

De Witte (1999) provides a review of the psychological literature on the relationship of perceived job insecurity and psychological well-being. He summarizes from the literature that job insecurity reduces significantly the well-being in different psychological domains. He also analyzes the question how important job insecurity is compared to the effect of unemployment. His empirical findings suggest that the anticipation of unemployment has the same impact as unemployment on the psychological well-being. His results confirm a statement which Lazarus already made in 1966, that "the anticipation of harm can have effects as potent as experiencing the harm itself" (quoted by Roskies et al. (1993, p.619))

Dekker and Schaufeli (1995, p.58) state that in the psychological literature it has become apparent that the phase of job insecurity, in which termination is more or less anticipated, may very well be the most stressful aspect of the whole unemployment process. They compare two groups of employees in a large Australian public transport organization who at the same time faced uncertainties about whether or not they will become 
unemployed due to organizational changes. They find that the psychological well-being of those who became unemployed in the next period improved compared to those who were still uncertain at this point. This result indicates that uncertainty about the future employment status not only affects mental well-being directly but also the perception of the unemployment status. Although one group of employees was finally made redundant they experienced an increase in their psychological well-being. They felt relieved from their uncertainty as they became unemployed according to their expectation.

Green et al. (2000) on the other hand analyzed which factors determine perceived job insecurity. They find that for the employed higher levels of unemployment rates increase perceived job insecurity, and higher levels and increases in unemployment rates also increase perceived difficulties of re-employment for the unemployed.

In this paper we bring together the several findings from the economic and psychologic literature on unemployment and mental well-being and provide an explanation of the mechanism how unemployment rates and anticipation of unemployment affect the perception of unemployment based on economic theory. The theoretical foundation for the econometric analysis comes from models with reference-dependent preferences with endogenous reference points developed in the behavioral economics literature. These models formalize the effect of the anticipation of an event as well as the effect of a deviation of what an individual had expected as an outcome for this event.

Furthermore, our analysis differs from the previous studies in the sense that changes rather than levels of the employment status are analyzed and that not the influence of only current unemployment rates or job prospects on current mental well-being is measured but the effect of expectations and deviations from the expected employment status on the perception of unemployment. From a prospect theoretical point of view it seems more plausible that changes in the employment status rather than the absolute status influence mental well-being and that the valuation of unemployment depends on a certain reference point. Kahneman and Tversky (1979, p.277) state: “...the carriers of value are changes in wealth or welfare, rather than final states. This assumption is compatible with basic principles of perception and judgment. Our perceptual apparatus is attuned to the evaluation of changes or differences rather than to the evaluation of absolute magnitudes. 
When we respond to attributes such as brightness, loudness, or temperature, the past and present context of experience defines an adaptation level, or reference point, and stimuli are perceived in relation to this reference point." Therefore, differences in the perception of unemployment regarding mental well-being are probably not only the result of social norms that are somehow derived from the unemployment rates but from potential deviations of the individual employment status from what an individual had expected, i.e. his reference point. The literature on reference-dependence provides a discussion of of the determination of reference points and mainly distinguishes exogenous and endogenous reference points. For our analysis the concept of endogenous expectation-based reference points proposed by Köszegi and Rabin $(2006 ; 2007 ; 2009)$ is applied. They propose that the individuals's reference-point is determined by lagged expectations about outcomes rather than the status quo. Several studies recently addressed their research questions to the empirical evidence of reference points that are determined by expectations. Abeler et al. (2011) show in an real-effort laboratory experiment that labor supply is in line with the predictions of models with reference dependent preferences with reference points formed by expectations. Crawford and Meng (2011) re-analyze the labor supply of New York City cab drivers and find empirical evidence for reference-dependence preferences with expectation based reference points. Card and Dahl (2011) analyze violent behavior dependent on outcomes of football games. They find that for unexpected losses of the home team violence against partners significantly increases whereas expected losses of the football team have no significant effect on at-home violence.

In our context, unemployment rates serve as an information that determines reference points of the individuals and the magnitude of changes in mental well-being is related to the deviation of this reference point. More precisely, we assume that individuals observe relevant unemployment rates (e.g. industrial sector specific or regional unemployment rates) and that they use this information to build expectations about their future employment status. These current expectations serve as the reference point for the future employment status. Finally, the individuals compare the actual outcome of their employment status with their expected outcome. If the actual employment status deviates from the expected employment status we expect a stronger effect from this outcome com- 
pared to the effect that arises when the actual employment status was already expected. More precisely for unemployment, we hypothesize that becoming unemployed is more has a more severe effect on mental well-being when unemployment hits the individual surprisingly rather than anticipated.

To test this hypothesis empirically it is essential to control for any unobserved individual level heterogeneity in mental well-being. As we focus on becoming or staying unemployed rather than being unemployed this leads naturally to a fixed effects estimator. We use the waves from 1998 to 2009 from the German Socio Economic Panel (SOEP) that provides all relevant information for our analysis.

In the next chapter we develop a simple theoretical model which motivates our empirical analysis. In chapter 3 we explain the regression model and the estimation strategy. Chapter 4 provides detailed information on the data set and variables used for the estimation. In chapter 5 we show and interpret the estimated effects. Finally, chapter 6 concludes.

\section{Theoretical Framework}

Theoretical models for reference-dependent preferences with endogenous reference points based on expectations from the behavioral economics literature deliver the theoretical background to our problem. These models support the idea that an individual is more affected by an outcome of an event that was not expected as if the same outcome was expected by the individual (see Section 1).

To motivate and structure the empirical analysis of reference-dependent effects of unemployment on mental well-being we borrow the formal structure of these theoretical models and substitute utility with the state of mental well-being. We can formalize the following theoretical model: 


$$
\begin{aligned}
M_{i t}\left(x_{i t}, x_{i t-1}, q_{i t}, q_{i t-1}\right) & =u\left(x_{i t}+x_{i t-1}\right)+v\left(q_{i t}+q_{i t-1}\right)+\mu\left(\left(1-x_{i t}\right)-q_{i t-1}\right) \\
\text { with } x_{i t} & = \begin{cases}1 & \text { if } i \text { unemployed in } t \\
0 & \text { if } i \text { employed in } t\end{cases} \\
\text { and } q_{i t} & = \begin{cases}1 & \text { if } i \text { has positive expectations in } t \\
0 & \text { if } i \text { has negative expectations in } t\end{cases}
\end{aligned}
$$

Overall mental well-being $M_{i t}(\cdot)$ for indvidual $i$ at time $t$ depends on the employment status $x$ in $t$ and $t-1, u(\cdot)$; on expectations about the future employment status $q$ in $t$ and $t-1, v(\cdot)$; and from a deviation of the current employment status in $t$ from the expected employment status for $t, \mu(\cdot)$.

$x_{i t}$ describes the current employment status in $t$ and takes the value 1 if the individual is unemployed in $t$ and 0 if he is employed in $t$.

Expectations $q$ are defined to be positive if an individual expects to be employed and to be negative if the individual expects to be unemployed in the future. For simplicity, we assume a binary outcome for expectations and $q_{i t}$ equals 1 for positive expectations in $t$ about the employment status in $t+1$, and $q_{i t}$ equals 0 for negative expectations in $t$ about the employment status in $t+1$.

As $M_{i t}(\cdot)$ depends on employment status at two different points in time, $t$ and $t-1$, we can distinguish four different cases of employment histories:

(1) $i$ is employed in $t$ and $t-1$

(2) $i$ is unemployed in $t$ and employed in $t-1$

(3) $i$ is employed in $t$ and unemployed in $t-1$

(4) $i$ is unemployed in $t$ and $t-1$.

Table 1 summarizes the four different cases.

Moreover, $M_{i t}(\cdot)$ depends on expectations in $t$ and $t-1$. Similarly to the unemployment histories we can distinguish 4 different case for the expectations histories: 
Table 1: Employment histories

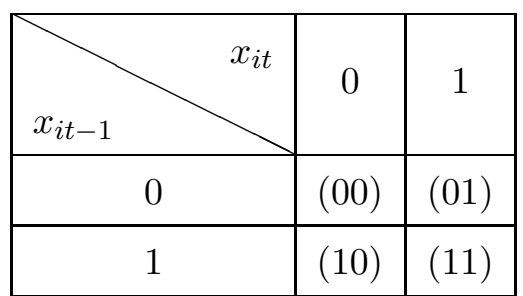

(i) negative expectations in $t-1$ and $t$

(ii) negative expectations in $t-1$ and positive expectations in $t$

(iii) positive expectations in $t-1$ and negative expectations in $t$

(iv) positive expectations in $t-1$ and $t$

The four cases of expectations histories can appear in each of the four cases of employment histories. Therefore, we can finally distinguish 16 different types of individuals regarding their unemployment status and expectations over two periods in time. Table 2 shows the different combinations of expectations and employment histories.

Table 2: Expectations and employment histories

\begin{tabular}{|c|c|c|c|c|c|}
\cline { 2 - 6 } \multicolumn{1}{c|}{} & $q_{i t-1}$ & \multicolumn{2}{c|}{0} & \multicolumn{2}{c|}{1} \\
\hline \multirow{2}{*}{$x_{i t-1}$} & $q_{i t}$ & 0 & 1 & 0 & 1 \\
\hline \multirow{2}{*}{0} & 0 & $(0000)$ & $(0001)$ & $(0010)$ & $(0011)$ \\
\cline { 2 - 6 } & $x_{i t}$ & $(0100)$ & $(0101)$ & $(0110)$ & $(0111)$ \\
\hline \multirow{2}{*}{1} & 0 & $(1000)$ & $(1001)$ & $(1010)$ & $(1011)$ \\
\cline { 2 - 6 } & 1 & $(1100)$ & $(1101)$ & $(1110)$ & $(1111)$ \\
\hline
\end{tabular}

Table 2 can be summarized in a compact employment-expectations matrix form with $j$ rows and $k$ columns.

$$
Z=\left(\begin{array}{llll}
0000 & 0001 & 0010 & 0011 \\
0100 & 0101 & 0110 & 0111 \\
1000 & 1001 & 1010 & 1011 \\
1100 & 1101 & 1110 & 1111
\end{array}\right)
$$


Each element $z_{j k}$ of the matrix contains the following information:

$$
z_{j k}=\left(\begin{array}{llll}
x_{i t-1} & x_{i t} & q_{i t-1} & q_{i t}
\end{array}\right) \text { with } j=1, \ldots, 4 \text { and } k=1, \ldots, 4 \text {. }
$$

All individuals in the first row of the employment-expectations matrix where employed in $t-1$ and $t$. All individuals in the second row where employed in $t-1$ and unemployed in $t$. All individuals in the third row where unemployed in $t-1$ and employed in $t$. All individuals in the last row where unemployed in $t-1$ and $t$. All individuals in the first column had negative expectations in $t-1$ and $t$. All individuals in the second column had negative expectations in $t-1$ and positive expectations in $t$. All individuals in the third column had positive expectations in $t-1$ and negative expectations in $t$. All individuals in the last column had positive expectations in $t-1$ and $t$. For example, the individual denoted with (0000) was employed in $t-1$ and $t$ and had negative expectations in $t-1$ and $t$, whereas the individual (0101) was employed in $t-1$, unemployed in $t$, had negative expectations in $t-1$ and positive expectations in $t$. Therefore, individuals (0110) and (0111) were employed in $t-1$ but became unemployed in $t$ although they had positive expectations about their employment status in $t-1$. Thus, these individuals became unemployed unexpectedly. Respectively, individuals (1110) and (1111) remained unemployed unexpectedly.

From the current empirical literature on unemployment and mental well-being and the theoretical literature on reference-dependence the following two hypothesis on the relationship between unemployment and mental well-being can be derived:

(i) In the case of becoming unemployed mental well-being deteriorates and in the case of becoming employed mental well-being increases.

(ii) If an individual has expected his current employment status his mental well-being is less affected by the outcome of his actual employment status as if he would not have expected his current employment status. More precisely in the case of unemployment, if an individual expected to become unemployed then the negative 
effect of becoming unemployed on mental well-being is less pronounced as if he would not have expected to become unemployed.

In the following Section the structure of the theoretical model formalized in this section is used as well as the consequential types of individuals to develop an econometric model that allows to test these hypothesis empirically.

\section{$3 \quad$ Empirical Strategy}

\subsection{Empirical Model}

In order to identify reference-dependent effects of unemployment on mental well-being empirically we translate Equation 1 into two different econometric models: first, a dummy variable model for all possible combinations of employment status and expectations in both periods, and second, model with pairwise interactions for employment status and expectations in both periods.

The dummy variable model follows straightforward from the theoretical model where 16 different cases of employment and expectations histories were distinguished. A dummy variable $d$ is used for each of the cases. For simplicity we preliminarily abstract from any additional influencing factors as well as from unobserved heterogeneity (both will be

introduced in the second regression model). We can write the following compact form of a linear regression model with $y_{i t}$ measuring mental well-being of individual $i$ at time $t$ :

$$
\begin{aligned}
& y_{i t}=\pi_{0}+\sum_{j=1}^{4} \sum_{k=1}^{4} \pi_{j k} d_{j k i t}-\pi_{11} d_{11 i t}+\epsilon_{i t} \\
& \text { with } \quad d_{j k i t}=\left\{\begin{array}{lllll}
1 & \text { if }\left(\begin{array}{llll}
x_{i t-1} & x_{i t} & q_{i t-1} & q_{i t}
\end{array}\right)=z_{j k} \\
0 & \text { otherwise }
\end{array}\right.
\end{aligned}
$$

Expanding Equation 3 yields the following dummy variable model: 


$$
\begin{aligned}
y_{i t}=\pi_{0} & +\pi_{12}(0001)_{i t}+\pi_{13}(0010)_{i t}+\pi_{14}(0011)_{i t} \\
& +\pi_{21}(0100)_{i t}+\pi_{22}(0101)_{i t}+\pi_{23}(0110)_{i t}+\pi_{24}(0111)_{i t} \\
& +\pi_{31}(1000)_{i t}+\pi_{32}(1001)_{i t}+\pi_{33}(1010)_{i t}+\pi_{34}(1011)_{i t} \\
& +\pi_{41}(1100)_{i t}+\pi_{42}(1101)_{i t}+\pi_{43}(1110)_{i t}+\pi_{44}(1111)_{i t} \\
& +\epsilon_{i t}
\end{aligned}
$$

Individual (0000) is arbitrarily chosen as the reference category. This model allows an immediate comparison of the mental well-being of different individuals. For example $\pi_{13}$ reflects the difference in mental well-being of an individual who in $t-1$ expected to stay employed in $t$ and the reference individual who in $t-1$ did not expect to stay employed in $t$, all else equal. In spite of its attractiveness for an easy comparison of individuals, this model does not allow for a non-ambiguous identification of referencedependent effects of unemployment on mental well-being. Suppose we were interested in the effect of becoming unemployed unexpectedly. As already shown in the theoretical model this situation is given in two cases. In the dummy variable model the effect of unexpected unemployment is captured by the coefficients of all individuals who where employed in $t-1$ and are unemployed in $t$ and had positive expectations in $t-1$. In this example this are the coefficients $\pi_{23}$ and $\pi_{24}$ (for individuals (0110) and (0111)). Both coefficients contain the effect from a deviation of the current employment status in $t$ from the expected employment status for $t$. But, these two individuals differ in their current expectations in $t$ about their future employment status in $t+1$. This difference is also captured by the coefficients $\pi_{23}$ and $\pi_{24}$. Thus, such a dummy variable model does not allow a unique identification of reference-dependent effects of unemployment. However, the structure of this model supports the later interpretation of the following econometric model with pairwise interactions of unemployment and expectations.

So far, we have not explicitly distinguished between different expectations about future employment status of the employed and the unemployed. The employed individuals build expectations about becoming unemployed or staying employed in the future. In contrast, the unemployed individuals build expectations about becoming re-employed or staying unemployed in the future. For the pairwise interacted model it will be differentiated 
between the expectations of the employed and the unemployed (as it is also done in the data, see Section 4). For the employed individual $i$ the expectation in $t$ about his employment status in $t+1$ is denoted by $\bar{q}_{i t}$. The expectation of an unemployed individual $i$ in $t$ about his employment status in $t+1$ is denoted by $\underline{q}_{i t}$. The outcomes of both variables are defined analogous to the general expectation $q_{i t}$ in Equation 1:

$$
\begin{aligned}
& \bar{q}_{i t}= \begin{cases}1 & \text { if the employed } i \text { in } t \text { expects to stay employed in } t+1 \\
0 & \text { if the employed } i \text { in } t \text { expects to become unemployed in } t+1\end{cases} \\
& \underline{q}_{i t}= \begin{cases}1 & \text { if the unemployed } i \text { in } t \text { expects to become re-employed in } t+1 \\
0 & \text { if the unemployed } i \text { in } t \text { expects to stay unemployed in } t+1\end{cases}
\end{aligned}
$$

Because, expectations $\bar{q}_{i t}$ and $\underline{q}_{i t}$ are mutually exclusive for individual $i$ in $t$ the distinction between expectations of the employed and unemployed was implicitly done before in the theoretical and the dummy variable model without loss of generality and in order to keep the notation easy.

With $\bar{q}_{i t}$ and $\underline{q}_{i t}$ the following pairwise interacted model that corresponds to Equations 1 and 3 can be obtained:

$$
\begin{aligned}
y_{i s t}=\beta_{0} & +\beta_{1} x_{i s t}+\beta_{2} x_{i s t-1} \\
& +\beta_{3} \bar{q}_{i s t}+\beta_{4} \underline{q}_{i s t} \\
& +\beta_{5} \bar{q}_{i s t-1}+\beta_{6} \underline{q}_{i s t-1} \\
& +\beta_{7}\left(x_{i s t} \times x_{i s t-1}\right) \\
& +\beta_{8}\left(\bar{q}_{i s t} \times \bar{q}_{i s t-1}\right)+\beta_{9}\left(\bar{q}_{i s t} \times \underline{q}_{i s t-1}\right) \\
& +\beta_{10}\left(\underline{q}_{i s t} \times \bar{q}_{i s t-1}\right)+\beta_{11}\left(\underline{q}_{i s t} \times \underline{q}_{i s t-1}\right) \\
& +\beta_{12}\left(\bar{q}_{i s t-1} \times x_{i s t}\right)+\beta_{13}\left(\underline{q}_{i s t-1} \times x_{i s t}\right) \\
& +\beta_{14}\left(\bar{q}_{i s t} \times x_{i s t-1}\right)+\beta_{15}\left(\underline{q}_{i s t} \times x_{i s t-1}\right) \\
& +w_{i s t} \boldsymbol{\beta}+\alpha_{i}+\delta_{s}+\lambda_{t}+\left(\delta_{s} \times \lambda_{t}\right)+\varepsilon_{i s t}
\end{aligned}
$$


$y_{i s t}$ measuring mental well-being of individual $i$ in federal state $s$ at time $t$. As mentioned earlier it is assumed that people use a certain unemployment rate to build expectations about their own employment status (see Section 1). In the empirical analysis we focus on unemployment rates at the federal state level. ${ }^{1}$ In order to control for possible correlation between individuals at this level the federal state where each individual lives is additionally picked up by the subscript $s$.

As before, $x_{i s t}$ takes the value 1 if the individual $i$ in federal state $s$ is unemployed in t. $\bar{q}_{i s t}$ and $\underline{q}_{i s t}$ take the value 1 for positive expectations in $t$ about the future employment status in $t+1$ of the employed and the unemployed in federal state $s$, respectively.

To measure causal effects of unemployment on mental well-being it is necessary to control for any factors that influence mental well-being as well as unemployment. $w_{i s t}$ is a vector of control variables at the individual level. $\alpha_{i}$ captures all time-invariant unobserved individual heterogeneity. $\delta_{s}$ captures all time-invariant unobserved heterogeneity at the federal state level, and $\lambda_{t}$ captures time fixed effects. The interaction of $\delta_{s}$ and $\lambda_{t}$ controls for all federal state specific effects that vary over time. This includes for example unemployment rates at the federal state level but also more generally all time-variant unobserved heterogeneity between federal states. Modeling explicitly federal state specific time-variant heterogeneity captures all possible correlation between individuals in the same federal state. Instead of interactions also clustered standard errors at the level of federal states could have used to allow for correlation between individuals in the same federal states. But clustered standard errors at this level impose problems with those individuals who move between federal states and clustering in this case would need additional correction of degrees of freedom in the model. We also avoid the alternative to just exclude all individuals who moved between federal states as this would not only impose a general loss of information but could also lead to biased estimates due to selection if individuals who move between federal states systematically differ in their characteristics from individuals who not move. $\varepsilon_{i s t}$ is the usual idiosyncratic error term.

\footnotetext{
${ }^{1}$ However, we have run the same regression models with data on the industrial sector level (2-digit NACE code) rather than on the federal state level. As the results barely change they are not shown in this paper but are available upon request from the author.
} 
The coefficients $\beta_{1}$ to $\beta_{6}$ measure direct effects from current and past unemployment and current and past positive expectations. Thus, the linear coefficients $\beta_{1}$ to $\beta_{6}$ reflect the functions $u(\cdot)$ and $v(\cdot)$ in Equation 1 if we assume linearity for $u(\cdot)$ and $v(\cdot)$. The coefficients $\beta_{7}$ to $\beta_{15}$ measure the effects of all possible pairwise interactions of the employment status and expectations in two subsequent periods of time. Although $\beta_{12}$ and $\beta_{13}$ are effects of unexpected unemployment, we cannot derive the function $\mu(\cdot)$ in Equation (1) straightforward from this model. Only certain linear combinations of coefficients allow the interpretation of effects as a reflection of $\mu(\cdot)$. When interpreting the estimated effects in Chapter 5 this will be explained in detail. Table 3 provides a detailed interpretation of those coefficients in the model that are related to the employment status and expectations.

In order to find the effects that uniquely identify reference-dependent effects of becoming or staying unemployed we can link the pairwise interacted model to the dummy variable model. Table 20 shows the relevant coefficients for each of the 16 cases. As shown in Section 2 the individuals (0110) and (0111) are those of interest as these became unemployed unexpectedly in $t$. The only difference between these two are their expectations in $t$. From Table 20 it can be seen that individual (0111) differs from individual (0110) in the coefficients $\beta_{4}$ and $\beta_{10}$. Both effects stem from the positive expectations that individual (0110) has in $t$ in contrast to individual (0111). The coefficient that is unique for both individuals is $\beta_{12}$. This effect stems from the combination of positive expectations in $t-1$, employment in $t-1$ and unemployment in $t$, i.e. unexpected unemployment. Analogous, for the individuals (1110) and (1111) we find $\beta_{13}$ to be the coefficient that identifies the effect of remaining unemployed unexpectedly as $\beta_{13}$ stems from the combination of being unemployed in $t-1$ and $t$ but having positive expectations in $t-1$. Therefore, for becoming or staying unemployed the coefficients $\beta_{12}$ and $\beta_{13}$ uniquely identify reference-dependent effects from unemployment on mental well-being, respectively. However, in order to have a meaningful comparison of individuals it will be necessary to compare certain linear combinations of coefficients. To test the hypothesis that an individual who became unemployed unexpectedly suffers more from becoming unemployed than an individual who already expected the unemployment the linear combination of $\beta_{5}$ 
Table 3: Variables, coefficients, and corresponding measured effects

\begin{tabular}{|c|c|c|}
\hline Variable & Coefficient & Effect of \\
\hline$x_{i s t}$ & $\beta_{1}$ & current unemployment \\
\hline$x_{i s t-1}$ & $\beta_{2}$ & past unemployment \\
\hline $\bar{q}_{i s t}$ & $\beta_{3}$ & current positive expectations of the currently employed \\
\hline$\underline{q}_{i s t}$ & $\beta_{4}$ & current positive expectations of the currently unemployed \\
\hline $\bar{q}_{i s t-1}$ & $\beta_{5}$ & past positive expectations of the previously employed \\
\hline$\underline{q}_{i s t-1}$ & $\beta_{6}$ & previous positive expectations of the previously unemployed \\
\hline$x_{i s t} \times x_{i s t-1}$ & $\beta_{7}$ & continued unemployment \\
\hline $\bar{q}_{i s t} \times \bar{q}_{i s t-1}$ & $\beta_{8}$ & continued positive expectations of the continuously employed \\
\hline $\bar{q}_{i s t} \times \underline{q}_{i s t-1}$ & $\beta_{9}$ & $\begin{array}{l}\text { continued positive expectations of the previously unemployed } \\
\text { and currently employed }\end{array}$ \\
\hline$\underline{q}_{i s t} \times \bar{q}_{i s t-1}$ & $\beta_{10}$ & $\begin{array}{l}\text { continued positive expectations of the previously employed and } \\
\text { the currently unemployed }\end{array}$ \\
\hline$\underline{q}_{i s t} \times \underline{q}_{i s t-1}$ & $\beta_{11}$ & continued positive expectations of the continuously unemployed \\
\hline $\bar{q}_{i s t-1} \times x_{i s t}$ & $\beta_{12}$ & $\begin{array}{l}\text { past positive expectations of the previously employed and cur- } \\
\text { rent unemployment }\end{array}$ \\
\hline$\underline{q}_{i s t-1} \times x_{i s t}$ & $\beta_{13}$ & $\begin{array}{l}\text { past positive expectations of the previously unemployed and } \\
\text { continued unemployment }\end{array}$ \\
\hline $\bar{q}_{i s t} \times x_{i s t-1}$ & $\beta_{14}$ & $\begin{array}{l}\text { current positive expectations of the currently employed and the } \\
\text { previous unemployment }\end{array}$ \\
\hline$\underline{q}_{i s t} \times x_{i s t-1}$ & $\beta_{15}$ & $\begin{array}{l}\text { current positive expectations of the currently unemployed and } \\
\text { the previous unemployment }\end{array}$ \\
\hline
\end{tabular}


and $\beta_{12}$ (and additionally $\beta_{10}$ in the case of positive expectations in $t$ ) is tested whether it is different from zero. The prediction is that this linear combination is negative, reflecting the additional negative effect that stems from the deviation of the expected employment status (i.e. 'employed in $t$ ') from the actual employment status ('unemployed in $t$ '). The detailed outline for the interpretation of the results is given in Chapter 5.2.

\subsection{Estimation strategy}

In order to identify a causal effect of unemployment on mental well-being it should be controlled for any heterogeneity that influences both mental well-being and unemployment. Panel data allow to account for any observed and unobserved determinants that are invariant over time or invariant over individuals or both. With interactions between federal states and time the model additionally controls for any federal state specific factors that vary over time (see Section 3.1). However, correlation over time within individuals that is not accounted for by any of the effects described can still be remaining. For example, unobserved factors at the individual level that evolve over time like life experience, perception of the relationship status, etc. that probably lead to a trend in mental wellbeing. This is reflected in an autocorrelated structure of the error term. Not accounting for such autocorrelation would lead to biased estimates of the standard errors of the coefficients and thus biased statistical tests. Therefore, heteroskedastic and autocorrelation consistent (HAC) standard errors by clustering at the individual level are estimated.

The dependent variable is subjective life satisfaction with outcomes on a scale from 0 (low) to 10 (high). Thus the dependent variable can be assumed to be cardinal as well as ordinal. Depending on the assumptions the estimation can be run with an linear estimator (e.g. ordinary least squares (OLS)) or an non-linear ordered latent response estimator (e.g. ordered probit or logit), respectively. Ferrer-i-Carbonell and Frijters (2004) provide an analysis of differences in estimated life satisfaction depending on the estimator. They show that using linear OLS and non-linear ordered response estimators essentially yield the same results for life satisfaction. They emphasize that controlling for time-invariant unobserved factors (individual fixed effects) matters to the estimates but not assumptions on cardinality or ordinality of life satisfaction. Therefore, we estimate mental well-being 
with OLS and control for time-invariant unobserved heterogeneity.

\subsubsection{Fixed and Random Effects Estimators}

In general there are two different estimators that allow to control for unobserved individual specific heterogeneity, the fixed effects and the random effects estimator. The two estimators differ in the assumptions on the individual effects. The fixed effects estimator explicitly models time-invariant individual effects as a determinant of the dependent variable. By demeaning the data over time the fixed estimator controls for all constant individual heterogeneity but inherently removes variation from the covariates. Identification relies on variation within individuals. The random effects estimator is based on the assumption that the time-invariant individual effects are random and uncorrelated with all other explanatory variables and are modeled as part of a composed error term. Identification with the random effects estimator relies on variation within and between individuals. Therefore, if the assumption of randomness of the time-invariant individual effects holds the random effect estimator is more efficient than the fixed effects estimator.

Because the random and the fixed effects estimators differ in the source of identification one should be aware of the exact question that is to be answered in the analysis. Whereas the coefficient of unemployment estimated with the random effects estimator can be interpreted as the effect of being unemployed on mental well-being, the coefficient of unemployment estimated with the fixed estimator reflects the effect of becoming unemployed on mental well-being. In this paper we analyze the effect of unexpected changes in rather than levels of the employment status on mental well-being. This leads directly to the fixed effects estimator. Nevertheless, in our context the random effects estimator could still deliver reasonable interpretation of the coefficients when changes rather than levels of the variables are used in the empirical model. However, it is essential to check whether the crucial assumption about no correlation between unobserved heterogeneity and the observables holds. This can be tested by conducting a variable addition test (VAT), where the dependent variable is regressed on the regressor matrices $X$ and $\bar{X}(X$ demeaned over time by individuals). ${ }^{2}$ The null hypothesis that the coefficients of $\bar{X}$ are

\footnotetext{
${ }^{2}$ The standard Hausman test in this case is problematic as it does not allow to perform the test with
} 
zero is tested with the classical F-Test. ${ }^{3}$

\subsubsection{Estimation of Effects for Different Parts of the Population}

The basic model is estimated for all individuals in the analysis data set (see Section 4). We are also interested whether certain groups in the population are affected differently from reference-dependent effects of unemployment on mental well-being and if the results from the basic estimation are robust for different parts of the population. It is focused on differences between genders and age groups. In order to keep the interpretation of results manageable, the basic pairwise interacted model (Equation 5) is estimated for various stratifications of the data rather than adding additional interactions terms for different groups in the population. Furthermore, in the model with individual fixed effects (see Section 3.2.1) only stratifying by gender allows the examination of gender specific differences. With individual fixed effects any time constant variables such as gender become zero when demeaning the data over time. Therefore a gender effect cannot be estimated with a fixed effects estimator.

\section{Data}

\subsection{Sample}

For the empirical analysis we use the waves from 1998 to 2009 from the German SocioEconomic Panel (SOEP). The SOEP started in 1984 with approximately 12000 individuals in 6000 households in West Germany and was extended to East Germany in 1990. After various sample refreshments the SOEP included more than 22000 adult respondents in approximately 12500 households in 2006 (Wagner et al., 2007). The data set contains information about the current employment status and expectations about the future employment status in each year. Unemployed individuals are asked for the reason

heteroskedastic and autocorrelation robust standard errors. Arellano (1993) developed a generalized VAT that is robust to autocorrelation and heteroscedasticity of arbitrary forms.

${ }^{3}$ See Baltagi (1998) and Arellano (1993) for further details and properties of this test. 
of their job termination. The SOEP also provides various measures for mental well-being (see below for further details) and socio-economic characteristics of the individuals.

In order to analyze the relevant part of the population we reduce the observations for the final analysis data set. Only those individuals are kept who are part of the economically active population. Therefore, the sample is restricted to individuals who are of age 30 to 55. The lower bound is to avoid the part of the population that is most probably still under education, or in a pecuniary and instable job situation. The upper bound is to avoid those individuals who already could face special incentives for job termination due to proximity to retirement, e.g. special regulations for early retirement. Among the employed individuals only those who are in full-time employment enter the sample. The restrictions imposed on the unemployed in the sample are in order to make these individuals most comparable to the employed. Therefore, only legally registered unemployed individuals who intend immediate full-time re-employment are kept. As the dependent variable in the model is a measure of mental well-being most probably reverse causality between mental well-being and unemployment would appear. People with mental health problems plausibly have a higher probability of becoming unemployed due to less productivity. Without further restrictions the estimation could suffer from an endogeneity problem. Following Schmitz (2011) we concentrate on those individuals with exogenous entries into unemployment due to plant closures to minimize the potential bias in the estimation of the effect of unemployment on mental well-being due to the endogeneity of unemployment. ${ }^{4}$

As a proxy for mental well-being we use life satisfaction that is self rated on a scale of 0 (low) to 10 (high). The SOEP would also allow to analyze the relationship between unemployment and mental health rather than mental well-being as it provides a measure for mental health, the Mental Component Summary Scale (MCS) ${ }^{5}$. But MCS is provided

\footnotetext{
${ }^{4}$ Schmitz (2011) shows that the general finding that unemployment has a negative effect on health is likely to be the result of biased estimates and does not reflect a causal relationship. With only plant closures as exogenous entries into unemployment he does not find any effect of unemployment on various health measures.

${ }^{5} \mathrm{MCS}$ is an scale score that is calculated using explorative factor analysis with various self-reported measures of mental health in the SOEP (see Andersen et al. (2007) for further information on the
} 
only every two years. As our model requires observations of two consecutive periods we loose too many observations with MCS. Therefore we concentrate on life satisfaction as a proxy for mental well-being. Table 4 shows correlation coefficients and p-values of life satisfaction and MCS with particular self-reported mental-health measures provided biannually in the SOEP.

\begin{tabular}{lllll} 
Table 4: Life satisfaction and mental health meas \\
\cline { 2 - 6 } Variables & \multicolumn{2}{c}{ Life Satisfaction } & \multicolumn{2}{c}{ MCS } \\
\hline MCS & 0.3940 & $(0.000)$ & & \\
pressed & -0.1937 & $(0.000)$ & -0.3567 & $(0.000)$ \\
melancholy & -0.4158 & $(0.000)$ & -0.6645 & $(0.000)$ \\
balanced & 0.3644 & $(0.000)$ & 0.6011 & $(0.000)$ \\
energy & 0.3534 & $(0.000)$ & 0.5376 & $(0.000)$ \\
acclessmental & -0.3717 & $(0.000)$ & -0.6737 & $(0.000)$ \\
lesscaremental & -0.3325 & $(0.000)$ & -0.6438 & $(0.000)$ \\
\hline$N$ & \multicolumn{5}{l}{} & \\
\hline
\end{tabular}

Not surprisingly the correlations between life satisfaction and certain mental-health measures are less pronounced than the correlations between MCS and the same mentalhealth measures as MCS is calculated on the basis of these variables. However, all correlations show the same sign as with MCS and are highly statistical significant. The strength of correlation varies more between MCS and mental-health measures than for life satisfaction. The correlation of life satisfaction and MCS is 0.39 and highly statistical significant. Therefore, life satisfaction could be interpreted as a proxy for mental health as well as for mental well-being. Nevertheless, we will interpret general life satisfaction as a measure of mental well-being as this interpretation seems to be more adequate in the context of utility which is the dependent variable in the theoretical models for reference-dependence.

algorithm). 


\subsection{Variables and Descriptive Statistics}

Table 5 reports summary statistics for the key variables of the analysis. The total number of observations in the analysis sample is 62135. The share of legally registered unemployed individuals is only $0.74 \%$. Rather than reflecting the true population unemployment rate in Germany this low share of unemployed is caused by the selection process of observations described above. The requirement of only exogenous entries into unemployment is very restrictive and a high fracture of unemployed individuals does not enter the sample.

Table 5: Summary statistics of life satisfaction, employment status, and expectations

\begin{tabular}{|c|c|c|c|c|c|c|c|c|c|}
\hline \multicolumn{5}{|c|}{ Employed } & \multicolumn{5}{|c|}{ Unemployed } \\
\hline \multicolumn{5}{|c|}{$N=61687$} & \multicolumn{5}{|c|}{$N=457$} \\
\hline \multicolumn{5}{|c|}{$99.26 \%$} & \multicolumn{5}{|c|}{$0.74 \%$} \\
\hline \multicolumn{10}{|c|}{$N=62135$} \\
\hline \multicolumn{10}{|c|}{ Employment Expectations } \\
\hline & very & somewhat & \multirow{2}{*}{\multicolumn{2}{|c|}{$\begin{array}{c}\text { not at all } \\
40.3 \%\end{array}$}} & \multirow{2}{*}{$\begin{array}{c}\text { impossible } \\
21.2 \%\end{array}$} & difficult & \multirow{2}{*}{\multicolumn{3}{|c|}{$\begin{array}{l}\text { easy } \\
4.5 \%\end{array}$}} \\
\hline & $15.4 \%$ & $44.3 \%$ & & & & $74.3 \%$ & & & \\
\hline \multicolumn{10}{|c|}{ Life Satisfaction } \\
\hline low & & & $\varnothing$ & high & low & $\varnothing$ & & & high \\
\hline 0 & $\begin{array}{lll}1 & 2 & 3\end{array}$ & $\begin{array}{lll}4 & 5 & 6\end{array}$ & 7 & $9 \quad 10$ & $\begin{array}{llll}0 & 1 & 2 & 3\end{array}$ & $\begin{array}{lll}4 & 5 & 6\end{array}$ & 7 & 8 & $9 \quad 10$ \\
\hline 0.2 & 0.20 .92 .1 & 3.110 .311$. & 25.232 . & 10.82 .8 & $\begin{array}{llll}1.1 & 2.0 & 5.0 & 9.6\end{array}$ & 9.425 .214 .2 & 16.4 & 13.6 & 2.60 .9 \\
\hline
\end{tabular}

Expectations about the future employment status are different for the employed and the unemployed (see also Section 3.1). In the SOEP questionnaires the employed individuals are asked about their concerns about their job security and can choose between three possible answers: very concerned, somewhat concerned, and not concerned at all. The unemployed are asked about their perceived difficulties to find an appropriate position and can choose between the categories: easy, difficult, and almost impossible. Comparing the distribution of answers over the three ordered categories of expectations very distinctive patterns for the employed and unemployed appear. About $40 \%$ of the employed are not concerned at all about their job security. But only $4.5 \%$ of the unemployed believe that it will be easy for them to find a new job. $15.4 \%$ of the employed are very concerned about 
their job security and $21.2 \%$ of the unemployed expect that it will be almost impossible to find a new job. Whereas $44.4 \%$ of the employed report to be somewhat concerned about their job security, $74.3 \%$ of the unemployed expect to have difficulties to find a new job. The descriptive statistics suggest that the unemployed tend to more pessimistic expectations about their employment future than the employed. In order to keep the interpretation of the estimated effects manageable we collapse the expectations into binary variables. Therefore, according to the theoretical model in Section 2 we will interpret the effect of positive expectations with reference to negative expectations. The response categories deliver a natural cut-off between negative and positive expectations (only the categories 'not at all' and 'easy' have a non-negative comprehension). Therefore, a dummy variable for positive expectations for the employed is defined that takes the value 1 for individuals who are 'not concerned at all' about their job security (corresponding to $\bar{q}_{i t}$ in Section 3.1). The choice of the cut-off between categories for the expectations of the unemployed is unfortunately not that clear-cut. The category 'easy' would be the natural outcome to define positive expectation. However, it cannot solely used because of the low share of respondents in this category. With only $4.5 \%$ of the unemployed in this category there would not be enough variation in the binary variable for positive expectations. Therefore, the cut-off is chosen between 'impossible' and 'difficult' and a dummy variable for positive expectations for the unemployed is defined that takes the value 1 if for individuals who expect that finding a new job will be 'easy' or 'difficult' but not 'impossible' (corresponding to $\underline{q}_{i t}$ in Section 3.1).

The dependent variable in the model is life satisfaction as a proxy for mental wellbeing. Individuals are asked to rate their overall life satisfaction on a scale from 0 (low) to 10 (high). The distribution of answers on this scale again is different for the employed and the unemployed. Whereas about $90 \%$ of the employed rate their life satisfaction between 5 and 9 with a peak in 8 , the variance of life satisfaction is higher for the unemployed. The mean life satisfaction for the employed is 7.1 and for the unemployed 5.5 (see also table 6). The standard errors for life satisfaction for the employed and unemployed are 1.59 and 2, respectively. Without controlling for any additional factors the average difference in life satisfaction between the employed and the unemployed is about 1.6 points. 
Table 6 additionally reports summary statistics for the control variables by employment status. We control for age, years of education, marital status (binary), number of children living in the same household, monthly net income, citizenship (binary), private health insurance (binary), blue-collar employment (binary), and self assessed health (scale from 1 (low) to 5 (high)). The employed and unemployed are on average similar in the control factors except net income and private health insurance. The fact that some unemployed have a positive net income at all (mean is 1.77 Euro per month) is because to some threshold the unemployed are allowed to earn some money without having affected their legal unemployment status and their unemployment benefits. Only $1 \%$ of the unemployed are privately insured compared to $13 \%$ of the employed. This difference can be explained by the German institutions for health insurance. In general only high income earners, self-employed, and civil servants are allowed to opt out from the public health insurance. When becoming registered as unemployed the privately insured typically have to switch back into the public system. However, there are some exceptions from this and under certain circumstances the unemployed are allowed to stay in the private system (mainly on their own expenses).

Table 6: Summary statistics for controls and dependent variable

\begin{tabular}{lrrrrrr}
\hline & \multicolumn{2}{c}{ All } & \multicolumn{3}{c}{ Unemployed } & \multicolumn{2}{c}{ Employed } \\
\cline { 2 - 7 } Variable & Mean & SD & Mean & SD & Mean & SD \\
\hline Life Satisfaction & 7.05 & 1.60 & 5.46 & 2.00 & 7.06 & 1.59 \\
Age & 42.72 & 7.00 & 42.45 & 6.96 & 42.72 & 7.00 \\
Years of Education & 12.59 & 2.70 & 11.68 & 2.43 & 12.60 & 2.70 \\
Married & 0.71 & 0.45 & 0.58 & 0.49 & 0.71 & 0.45 \\
Number of Children in Household & 0.79 & 0.97 & 0.81 & 1.02 & 0.79 & 0.97 \\
Net Income & 1675.50 & 992.77 & 1.77 & 37.90 & 1687.90 & 985.89 \\
Foreign & 0.07 & 0.26 & 0.08 & 0.27 & 0.07 & 0.26 \\
Private Insurance & 0.13 & 0.34 & 0.01 & 0.11 & 0.13 & 0.34 \\
Blue Collar & 0.33 & 0.47 & - & - & 0.33 & 0.47 \\
Self Assessed Health & 3.55 & 0.81 & 3.48 & 0.91 & 3.55 & 0.81 \\
\hline$N$ & 62135 & & 457 & & 61678 & \\
\hline
\end{tabular}




\section{$5 \quad$ Results}

\subsection{Variable Addition Test for Unobserved Heterogeneity}

In Section 3.2.1 the importance of testing for correlation between unobserved heterogeneity and the observed variables included in the model in order to decide whether the random effects estimator is applicable to our analysis was emphasized. We performed a VAT (see Section 3.2.1) following Arellano (1993). The usual F-Test rejects the joint null hypothesis that all coefficients of the demeaned explanatory variables are zero at the $0 \%$ significance level for all models (including all stratifications). Thus it is rejected, that none of the unobserved time-invariant heterogeneity captured by means over time is uncorrelated with the observed explanatory variables. So the random effects estimator is not applicable in our case as its crucial assumption of independence of the unobserved heterogeneity is rejected. Therefore, we rely the interpretation of the estimated effects of on the results from the fixed effects estimation.

\subsection{Interpretation Strategy of the Results}

For the interpretation of effects the results are examined in three steps following the structure of the two empirical models that were introduced in Section 3.1.

First, individuals that are employed and unemployed in $t$ each with the same expectations history and the same employment status in $t-1$ are compared pairwise. In particular, we compare the following pairs that were employed in $t-1$ : (0000) and (0100), (0001) and (0101), (0010) and (0110), and (0011) and (0111). We compare the following pairs that were unemployed in $t-1$ : (1000) and (1100), (1001) and (1101), (1010) and (1110), and (1011) and (1111). Applying hypothesis tests for multiple coefficients and calculating linear combinations of coefficients this kind of comparison allows to analyze whether or not comparable employed and unemployed individuals differ significantly in their mental well-being at all and to quantify the magnitude of such a difference.

In the second step, individuals that were employed in $t-1$ and became unemployed in $t$ but with different expectations regarding their employment status in $t$ are compared. In particular, we compare individuals (0101) and (0111), and (0100) and (0101). It is 
tested whether individuals who became unemployed unexpectedly differ from individuals who expected their unemployment.

Finally, the coefficient that uniquely measures the effect that originates from the unexpectedness of unemployment on mental well-being is interpreted in order to quantify the reference-dependent effect of unemployment on mental well-being.

The interpretation of the results follows the same three step structure for all stratifications.

\subsection{Results from Fixed Effects Estimation for All Individuals}

Table 7 reports the estimated OLS coefficients for the pairwise interacted fixed effects model applied to the whole sample. The estimates correspond to the coefficients in Equation 5 of the theoretical regression model introduced in Section 3.2.

\subsubsection{Differences between employed and unemployed}

As explained above we first concentrate on the difference in mental well-being between the employed and unemployed. Table 8 shows the results of calculated and F-tested linear combinations of estimated coefficients that reflect the differences in mental well-being between comparable pairs of employed and unemployed individuals. The second and the third columns report comparisons of currently employed and unemployed. Whereas in the second column both individuals were employed in $t-1$ the individuals compared in the third column were both unemployed in $t-1$. In the rows the pairs of currently employed and unemployed are separated by their histories of expectation.

The first cell shows the difference in mental well-being of currently employed and currently unemployed individuals where both individuals were employed in $t-1$ and both had negative expectations in $t-1$ and in $t$ and all else equal. The mental well-being of this pair differs in the coefficient $\beta_{1}$ and is on average 0.3032 points lower for these unemployed than the mental well-being of the compared employed. The null hypothesis that $\beta_{1}$ equals zero cannot be rejected at a significance level lower than $19.02 \%$. Therefore, we do not

find a significant difference in the mental well-being of employed and unemployed with currently negative expectations when both were employed and had negative expectations 
in the past period.

Comparing currently employed and unemployed with negative expectations in both periods but unemployment in $t-1$ the linear combination of $\beta_{1}$ and $\beta_{7}$ is not statistically significant different from zero just at the $10 \%$ significance level. Thus, independent from the past employment status we find no statistically significant difference in the mental well-being of employed and unemployed if negative expectations are present in $t$ and $t-1$. The effects of negative expectations in two consecutive periods seem to dominate any difference in mental well-being between employed and unemployed individuals that stems from the difference in the employment status.

The mental well-being of currently employed and unemployed differs statistically highly significant for all other combinations of expectations and employment histories. The highest difference in mental well-being appears between those employed and unemployed who had negative expectations in $t-1$ but positive expectations in $t$ (between (1001) and (1101)). In this case we observe the difference in mental well-being of an individual that became employed unexpectedly in $t$ (a positive deviation from the reference point) and adjusted expectations in $t$ and an individual that remained unemployed expectedly (no deviation from the reference-point) and also with positive expectations in $t$. This result can be seen as a first empirical hint to reference-dependence in the context of employment and unemployment. Also, the average difference of 1.91 and 1.72 points in mental well-being of the employed and unemployed with positive expectations in $t-1$ and negative expectations in $t$ and past employment and unemployment respectively is not only statistically significant but substantial. In both cases we observe individuals who became unemployed unexpectedly and adjusted their expectations in $t$ downwards. Thus, the comparison of employed and unemployed individuals already shows evidence for reference-dependent effects of the employment status on mental well-being as the biggest differences in mental-well being can be found for those cases where a change in the employment status was unexpected. 


\subsubsection{Differences between expected and unexpected unemployment and the reference-dependent effect}

In the following we concentrate on those individuals that became unemployed unexpectedly. Becoming unemployed unexpectedly requires employment and positive expectations in $t-1$ and unemployment in $t$. Therefore, the individuals of interest are (0110) and (0111). Both were employed in $t-1$, are unemployed in $t$, and had positive expectations in $t-1$. The only difference in both individuals lies in their expectations in $t$. Individual (0110) has in $t$ negative expectations about becoming re-employed in $t+1$ whereas individual (0111) has in $t$ positive expectations. As we are interested in the effect of unexpected unemployment on mental well-being we compare the two types of unexpected unemployed to those unemployed individuals who expected their unemployment but have the same expectations in $t$ and all else equal. In this sense the compared individuals have the same employment histories and the same expectations in $t$ but differ in their expectations in $t-1$. This makes two comparable pairs: individuals (0100) versus (0110), and (0101) versus (0111). Both pairs were employed in $t$ and unemployed in $t-1$. Within both pairs the individuals differ in their expectations in $t-1$ but agree in their expectations in $t$. Between pairs the difference lies in their expectations in $t$, where the first pair has negative expectations and the latter pair positive expectations in $t$.

Table 9 shows the results of calculated and F-tested linear combinations of estimated coefficients that reflect the differences in mental well-being between comparable pairs of individuals who became expectedly and unexpectedly unemployed.

The first cell shows the estimated average difference in mental well-being between unexpected and expected unemployed with negative expectations in $t$ for both. The difference in mental well-being between these two individuals is reflected by the linear combination of $\beta_{5}$ and $\beta_{12}$. The estimated difference in life satisfaction is 1.54 points. The F-test rejects the null hypothesis that the linear combination of $\beta_{5}$ and $\beta_{12}$ equals zero at an acceptable $5.75 \%$ significance level. Thus, an individual that did not expect to become unemployed has on average a by 1.5 points lower life satisfaction compared to an individual who expected his unemployment, all else equal. This applies for unexpected unemployment, when expectations about future employment are adjusted downwards in the 
period of becoming unemployed. In contrast, we find no statistically significant difference in mental well-being between unexpected and expected unemployed when expectations remain and become positive in $t$, respectively. The distinguishing linear combination of coefficients in this case is $\beta_{5}+\beta_{10}+\beta_{12}$. The estimated coefficient of this linear combination is -0.04 points in life satisfaction and is not statistically significant different from zero. Thus, individuals who became unemployed unexpectedly but who have still positive expectations about their future employment status are not different from those unemployed who expected to become unemployed but also have positive expectations about their future employment. Thus, depending on the expectations in $t$ we find a reference-dependent effect of unemployment on mental well-being. Whereas individuals with current positive expectations seem not to be affected by the fact that their unemployment was not expected, we find for individuals who are pessimistic about their future employment status a clear negative effect that stems from the unexpectedness of their unemployment. A detailed look at the estimated coefficients in the particular linear combinations reveals the mechanism of this difference.

Again, Table 7 shows in particular the estimated coefficients that contribute to the calculation of the linear combinations above. First of all, the coefficient of the variable $\left(\bar{q}_{i s t-1}\right)\left(x_{i s t}\right), \beta_{12}$, is the one which uniquely measures the reference-dependent effect of becoming unemployed unexpectedly. For both types of individuals who became unexpectedly unemployed this coefficient is part of the linear combinations of coefficients that distinguish them from the expectedly unemployed. The estimate is -1.6 and statistically significant at the $5 \%$ level. For both types of unexpectedly unemployed individuals this result shows an average drop in life satisfaction of almost 2 points. Again, this negative effect only stems from the unexpectedness of their unemployment. However, both types benefit from their positive expectations in $t-1$. This effect is reflected in the coefficient of the variable $\bar{q}_{i s t-1}, \beta_{5}$. The estimate of this coefficient is 0.07 and statistically significant at a lower than $1 \%$ level. However, compared to individuals who expected their unemployment, all else equal, this positive effect is not able to outweigh the negative effect from the unexpected unemployment. Therefore, the results suggest that the unexpected incidence of unemployment worsens the situation for the unemployed. Focusing 
on those unexpectedly unemployed with ongoing positive expectations the coefficient of

the variable $\left(\underline{q}_{i s t}\right)\left(\bar{q}_{i s t-1}\right), \beta_{10}$, is of additional relevance. This coefficient captures the effect of continued positive expectations in the case of becoming unemployed in $t$. The estimate is 1.5 and statistically significant at the $10 \%$ level. In absolute values the estimate of $\beta_{10}$ is close to the estimate of $\beta_{12}$. The fact that these individuals in spite of their unexpected unemployment go on with positive expectations makes them statistically not distinguishable to those individuals who expected their unemployment. The positive effect from ongoing positive expectations outweighs the negative effect from unexpected unemployment.

In summary these results show a general reference-dependent negative effect for all individuals that became unemployed unexpectedly. This effect stems from the unexpectedness of unemployment, i.e. a negative deviation from the reference point. Individuals who have negative expectations about their job future after they became unemployed unexpectedly, i.e. individuals who adjusted their expectations downwards after becoming unemployed unexpectedly directly suffer from the negative deviation of their employment status from their reference point. Their positive expectations in the period prior to their unemployment cannot outweigh the negative effect from the unexpected unemployment. In contrast, individuals who became unemployed unexpectedly but with unaffected positive expectations about their future employment are statistically not different from those who became unemployed expectedly. This similarity is owed to the fact that in this case the positive effect from ongoing positive expectations outweighs the negative effect from unexpected unemployment.

\subsection{Results from Fixed Effects Estimation by Age Groups}

In order to estimate different slopes of the regression line for different ages the data set is stratified in two age groups (similar to using interaction terms). The number of only two sub-samples is mainly driven by the limited number of observed unemployed individuals. The first sub-sample includes individuals of age 30 to 40 (24 731 observations) and the second sub-sample includes individuals of age 41 to 55 (37 404 observations). Table 21 shows the distributions of life satisfaction and expectations over age years by employment 
status. Average life satisfaction in the older age groups (6.99 and 5.31 for the employed and unemployed, respectively) is slightly lower than in the younger group (7.16 and 5.18 for the employed and unemployed, respectively). However, the average share of unemployed with positive expectations in the older age group is about $12 \%$ points lower than in the younger age group $(83.4 \%$ and $71.7 \%)$. There is no such a clear difference in average expectations between younger and older employed individuals (40.7\% and 40.1\%).

The estimated coefficients for the younger age group mainly confirm the findings from the basic estimation, see Table 15. Table 16 reports the results for the estimated differences in life satisfaction between employed and unemployed young individuals. Again, the highest differences in life satisfaction between employed and unemployed individuals is found for unexpected outcomes in the employment status with adjusted expectations in the next period. The estimated difference between individuals who became unexpectedly employed and individuals who expectedly remained unemployed with an upward adjustment of expectations, (1010) and (1110), is 3.87 points in life satisfaction $(0.2 \%$ significance level). Also, individuals who became unexpectedly unemployed followed by downward adjusted expectations have a 2.8 points lower life satisfaction than comparable employed individuals ( $0.0 \%$ significance level). In both cases the difference in life satisfaction exceeds the overall difference in life satisfaction between employed and unemployed individuals, see Section 4.2.

For the older age group the results suggest only minor differences in life satisfaction between employed and unemployed individuals, see Table 17. Moreover, the unexpectedness of the employment status outcome in cases with adjusted expectations in the next period seems not to play a role. Only in the case with unexpected ongoing unemployment and downward adjusted expectations ((1010) versus (1110)) the estimated difference in life satisfaction of 1.88 points is significant at the $0.0 \%$ level.

These findings for both age groups are also reflected in the estimated differences in life satisfaction between expected and unexpected unemployed indivduals, see Table 18 and Table 19. For the younger age group the reference-dependent effect $\left(\beta_{12}\right)$ is -1.9 and highly significant. This effect is only slightly lowered by the highly significant effect of previous positive expectations $\left(\beta_{5}\right), 0.1$. Thus, the overall reduction in life satisfaction 
that occurs because the unemployment was not expected is estimated with 1.8 points ( $0.1 \%$ significance level). In the case where positive expectations are not affected by the unemployment a significant reference-dependent effect does not appear.

As expected from the comparison of life satisfaction levels between employed and unemployed individuals in the older age group the results suggest no empirical evidence for reference-dependent effects of unemployment for this part of the population.

A general higher fluctuation in the job market for younger individuals in the data set could be supposed as a possible explanation for this result. Table 23 shows the numbers of observations for all appearing counts of total unemployment periods per individual. The distribution of total counts is almost the same for the younger and older age group. Thus, a higher volatility for younger individuals between employment and unemployment periods seems not to be the reason for our findings.

Another explanation could be that younger individuals tend to be less risk averse than older individuals. Therefore, they might choose jobs with general lower job security such as in young and developing startup companies with a higher probability than more risk averse older individuals. However, we run the same regression with industrial fixed effects instead of federal state fixed effects and find similar results.

We tend towards the level of expertness on the job market as the most plausible explanation for the difference between younger and older individuals. Whereas older individuals might be more experienced in the evaluation of information regarding their future employment status, younger individuals seem to be less able to anticipate potential unemployment. The difference in the ability of foreseeing unemployment between younger and older individuals is supported by the data, see Table $22.19 .1 \%$ of the younger individuals who became unemployed did not expect their unemployment, whereas only $5.2 \%$ of the older age group became unemployed without expecting it. Not such a clear but similar pattern can be found for those individuals who stayed unemployed. $75.8 \%$ of the younger unemployed in $t-1$ who stayed unemployed in $t$ had positive expectations for $t$ whereas the share amongst the older unemployed is $70 \%$. These numbers suggest that too few individuals in the older age class did not expect to become unemployed to show a statistically significant reference-dependent effect of unemployment on mental well-being 
among this group.

\subsection{Results from Fixed Effects Estimation by Gender}

The estimated coefficients for the stratified data by gender mainly confirm the findings from the basic estimation.

For men we find a statistically significant lower life satisfaction by 1.3 points on average for unemployed even with negative expectations in $t-1$ and $t$ and unemployment in $t-1$ for both, see Table 11. However, there is no significant difference between employed and unemployed males when both were employed in $t-1$ and unemployment was not expected and expectations adjusted downwards in $t((0010)$ versus (0110)). This result is also reflected in Table 13. Whereas the results of the basic estimation suggest a statistically significant difference in life satisfaction of expectedly and unexpectedly unemployed individuals with downward adjusted expectations in $t$ this is not the case for males. The linear combination of $\beta_{5}$ and $\beta_{12}$ shows a lower life satisfaction by 1.3 points for unexpectedly unemployed but the difference is not statistically significant. For a deeper insight we estimated a further stratification for males by age and find that only for males of age 41 to 55 no reference-dependent effect appears. For males of age 30 to 40 we find a drop in life satisfaction by 2.3 points on average ( $0.3 \%$ significance level) caused by the unexpectedness of unemployment when expectations are adjusted downwards. Again, this result reflects the differences between age groups as discussed in Section 5.4. Interestingly, for younger men when expectations are adjusted upwards or remain positive after becoming unemployed the effect of ongoing expectations not only outweighs the negative effect from unexpected unemployment but even exceeds it $\left(\beta_{10}=3.27\right.$ at $0.1 \%$ significance level).

For females we find similar results as in the basic estimation as well as in the comparison of employed and unemployed (see Table 12) as in the comparison of expected and unexpected unemployment (see Table 13). In the case of downward adjusted expectations after becoming unemployed unexpectedly the average reference-dependent effect is -2.11 points in life satisfaction. With no adjustment of expectations we find no referencedependent effect for females. The results of the regression for the further stratified female sub-sample into age groups suggest no differences between older and younger women 
regarding reference-dependent effects of unemployment on mental well-being.

Summarizing this subsection, we find empirical evidence for reference-dependent effects of unemployment on mental well-being for women and young men. Only for older men the results suggest no evidence for reference-dependence in the context of unemployment.

\section{Conclusion}

Our empirical results show that mental well-being of individuals who expected to become unemployment is less affected from becoming unemployed as if the unemployment was not expected previously. We find that current and past expectations about the future employment status have an important impact not only directly on mental well-being but also on the perception of the employment status. Our results are derived from the estimation of an econometric model which follows the structure of theoretical models with reference dependent preferences and endogenous reference points that are determined by lagged expectations. We assumed that unemployment rates are used as an information to build expectations about the future employment status and lagged expectations represent the reference point. We developed the hypothesis that depending on expectations (i.e. the reference point) becoming unemployed affects the individuals differently.

The contribution of our study is twofold. First, we add to the literature on unemployment and mental well-being where the mechanism of how unemployment rates and expectations affect the perception of unemployment remained unclear so far. Whereas in this strand of literature only current expectations about the future are taken into account we show that past expectations play an important role in the perception of unemployment. We find that previously expecting unemployment attenuates the negative effect from becoming unemployed. It seems important to give individuals sufficient notice of their unemployment so that they are able to anticipate their unemployment and probably adapt to this situation. On the other hand it can be important to re-employment programs to focus on individuals who became unemployed unexpectedly in particular as the higher drop in mental well-being may involve a higher risk of developing serious mental illnesses. This in turn can reduce the chances of re-employment. Our results show that 
positive expectations about re-employment even in the case of unexpected unemployment are able to keep up mental well-being at the level as if the unemployment was expected.

Second, our finding that unexpected unemployment has a stronger negative impact on mental well-being than expected unemployment supports theoretical models with reference dependent preferences and endogenous reference point formation with empirical evidence. Therefore, we also contribute to the literature on the importance of reference points (DellaVigna (2009) for an overview). Our results suggest that lagged expectations about the future employment status indeed serve as reference point and that the size of the effect of unemployment on mental well-being reflects a deviation from an individual reference point rather than the final state of unemployment. 


\section{References}

[1] Abeler, Johannes, Armin Falk, Lorenz Goette, and David Huffman (2011). Reference Points and Effort Provision. textitAmerican Economic Review, 101(2), 470-92.

[2] Andersen, Hanfried H., Axel Mühlbacher, Matthias Nübling, Jürgen Schupp, Gert G. Wagner (2007). Computation of Standard Values for Physical and Mental Health Scale Scores Using the SOEP Version of SF12v2. Journal of Applied Social Science Studies, 127(1), 171-182.

[3] Arellano, Manuel. 1993. On the Testing of Correlated Effects with Panel Data. Journal of Econometrics, 59(1-2), 87-97.

[4] Baltagi, Badi H. (1998). Panel Data Methods. Handbook of Applied Economic Statistics, Aman Ullah and David E.A (eds). Giles, Marcel Dekker, New York.

[5] Card, David and Gordon Dahl (2011). Family Violence and Football: The Effect of Unexpected Emotional Cues on Violent Behavior. The Quarterly Journal of Economics, 126(1), 103-143.

[6] Clark, Andrew E., and Andrew J. Oswald (1994). Unhappiness and Unemployment. The Economic Journal, 104(424), 648-659.

[7] Clark, Andrew E., Yannis Georgellis, and Peter Sanfey (2001). Scarring: The Psychological Impact of Past Unemployment. Economica, 68(270), 221-241.

[8] Clark, Andrew E., Andreas Knabe, and Steffen Rätzel (2009). Unemployment as a Social Norm in Germany. Journal of Applied Social Science Studies, 129(2), 251-260.

[9] Crawford, Vincent P., and Juanjuan Meng (2011). New York City Cabdrivers' Labor Supply Revisited: Reference-Dependent Preferences with Rational-Expectations Targets for Hours and Income. American Economic Review, 101(5), 1912-1932.

[10] De Witte, Hans (1999). Job Insecurity and Psychological Well-being: Review of the Literature and Exploration of Some Unresolved Issues. European Journal of Work and Organizational Psychology, 8(2), 155-177. 
[11] Dekker, Sidney W.A., and Wilmar B. Schaufeli (1995). The Effects of Job Insecurity on Psychological Health and Withdrawal: A Longitudinal Study. Australian Psychologist, 30(1), 57-63.

[12] DellaVigna, Stefano (2009). Psychology and Economics: Evidence from the Field. Journal of Economic Literature, 47(2), 315-72.

[13] Ferrer-i-Carbonell, Ada and Paul Frijters (2004). How Important is Methodology for the estimates of the determinants of Happiness? The Economic Journal, 114(497), 641-659.

[14] Green, Francis, Alan Felstead, and Brendan Burchell (2000). Job Insecurity and the Difficulty of Regaining Employment: An Empirical Study of Unemployment Expectations. Oxford Bulletin of Economics and Statistics, 62(s2), 855-883.

[15] Kahneman, Daniel and Amos Tversky (1979). Prospect Theory: An Analysis of Decision under Risk. Econometrica, 47(2), 263-292.

[16] Knabe, Andreas and Steffen Rätzel (2011). Scarring or Scaring? The Psychological Impact of Past Unemployment and Future Unemployment Risk. Economica, 78(310), 283-293.

[17] Kőszegi, Botond and Matthew Rabin (2006). A Model of Reference-Dependent Preferences. The Quarterly Journal of Economics, 121(4), 1133-1166.

[18] Kőszegi, Botond and Matthew Rabin (2007). Reference-Dependent Risk Attitudes. American Economic Review, 97(4), 1047-1073.

[19] Kőszegi, Botond and Matthew Rabin (2009). Reference-Dependent Consumption Plans. American Economic Review, 99(3), 909-936.

[20] Roskies, Ethel, Christiane Louis-Guerin, and Claudette Fournier (1993). Coping with job insecurity: How does personality make a difference? Journal of Organizational Behavior, 14(7), 617-630. 
[21] Ruhm, Christopher J. (2000). Are Recessions Good for your Health? The Quarterly Journal of Economics, 115(2), 617-650.

[22] Ruhm, Christopher J. (2003). Good times make you sick. Journal of Health Economics, 22(4), 637-658.

[23] Ruhm, Christopher J. (2005). Healthy living in hard times. Journal of Health Economics, 24(2), 341-363.

[24] Schmitz, Hendrik (2011). Why are the unemployed in worse health? The causal effect of unemployment on health. Labour Economics, 18(1), 71-78.

[25] Statistisches Bundesamt (2010), Fachserie 12, Reihe 7.2, 2002-2008.

[26] Vatter, Johannes (2012). Well-Being in Germany: What Explains the Regional Variation? SOEPpapers, 435-2012.

[27] Wagner, Gert G., Joachim R. Frick, and Jürgen Schupp (2007). The German SocioEconomic Panel Study (SOEP) - Scope, Evolution and Enhancements. Journal of Applied Social Science Studies, 127(1), 139-169.

[28] Winkelmann, Liliana, and Rainer Winkelmann (1998). Why Are the Unemployed So Unhappy? Evidence from Panel Data. Economica, 65(257), 1-15. 


\section{Appendix}

Table 7: Fixed effects estimates for life satisfaction - all indivduals

\begin{tabular}{|c|c|c|c|}
\hline Variable & & Coefficient & HAC SE \\
\hline$x_{i s t}$ & $\beta_{1}$ & -0.3032 & 0.2314 \\
\hline$x_{i s t-1}$ & $\beta_{2}$ & -0.1258 & 0.1371 \\
\hline $\bar{q}_{\text {ist }}$ & $\beta_{3}$ & $0.2147^{* * *}$ & 0.0195 \\
\hline$\underline{q}_{i s t}$ & $\beta_{4}$ & $-0.4892^{*}$ & 0.2593 \\
\hline $\bar{q}_{i s t-1}$ & $\beta_{5}$ & $0.0642^{* * *}$ & 0.0190 \\
\hline$\underline{q}_{i s t-1}$ & $\beta_{6}$ & 0.0399 & 0.1459 \\
\hline$x_{i s t} \times x_{i s t-1}$ & $\beta_{7}$ & -0.6005 & 0.5949 \\
\hline $\bar{q}_{i s t} \times \bar{q}_{i s t-1}$ & $\beta_{8}$ & -0.0198 & 0.0264 \\
\hline $\bar{q}_{i s t} \times \underline{q}_{i s t-1}$ & $\beta_{9}$ & $-0.6130^{*}$ & 0.3709 \\
\hline$\underline{q}_{i s t} \times \bar{q}_{i s t-1}$ & $\beta_{10}$ & $1.4960^{*}$ & 0.8750 \\
\hline$\underline{q}_{i s t} \times \underline{q}_{i s t-1}$ & $\beta_{11}$ & 1.2091 & 0.8602 \\
\hline $\bar{q}_{i s t-1} \times x_{i s t}$ & $\beta_{12}$ & $-1.6021^{* *}$ & 0.8098 \\
\hline$\underline{q}_{i s t-1} \times x_{i s t}$ & $\beta_{13}$ & -0.8131 & 0.6450 \\
\hline $\bar{q}_{i s t} \times x_{i s t-1}$ & $\beta_{14}$ & $0.6851^{*}$ & 0.3513 \\
\hline$\underline{q}_{i s t} \times x_{i s t-1}$ & $\beta_{15}$ & 0.0329 & 0.7730 \\
\hline Age & & $-0.0298^{*}$ & 0.0137 \\
\hline Years of Education & & -0.0185 & 0.0174 \\
\hline Married & & $0.1265^{* *}$ & 0.0361 \\
\hline Children in household & & 0.0189 & 0.0140 \\
\hline Net Income & & $0.0001^{* *}$ & 0.0000 \\
\hline Foreign & & 0.1573 & 0.1233 \\
\hline Private insurance & & 0.0440 & 0.0463 \\
\hline Blue collar & & -0.0359 & 0.0311 \\
\hline Self assessed health & & $0.4582^{* *}$ & 0.0107 \\
\hline Constant & & $6.6014^{* *}$ & 0.6638 \\
\hline$\alpha_{i}$ & & yes & \\
\hline$\delta_{s}$ & & yes & \\
\hline$\lambda_{t}$ & & yes & \\
\hline$\left(\delta_{s}\right)\left(\lambda_{t}\right)$ & & yes & \\
\hline$N$ & & 62135 & \\
\hline
\end{tabular}

Note: ${ }^{*} \mathrm{p}<0.1,{ }^{* *} \mathrm{p}<0.05,{ }^{* * *} \mathrm{p}<0.01$ 
Table 8: Employed versus unemployed - all indivduals

\begin{tabular}{|c|c|c|}
\hline$\left(q_{t-1} / q_{t}\right)$ & $(0 / 0)$ vs $(0 / 1)$ & $(1 / 0)$ vs $(1 / 1)$ \\
\hline$(0 / 0)$ & $\begin{array}{l}H_{0}: \beta_{1}=0 \\
\text { p-value }=0.1902 \\
\beta_{1}=-0.3032\end{array}$ & $\begin{array}{l}H_{0}: \beta_{1}+\beta_{7}=0 \\
\text { p-value }=0.1005 \\
\beta_{1}+\beta_{7}=-0.9037\end{array}$ \\
\hline$(0 / 1)$ & $\begin{array}{l}H_{0}: \beta_{3}=\beta_{1}+\beta_{4} \\
\text { p-value }=0.0000 \\
\left(\beta_{1}+\beta_{4}\right)-\left(\beta_{3}\right)=-1.0071\end{array}$ & $\begin{array}{l}H_{0}: \beta_{3}+\beta_{14} \\
=\beta_{1}+\beta_{4}+\beta_{7}+\beta_{15} \\
\text { p-value }=0.0021 \\
\left(\beta_{1}+\beta_{4}+\beta_{7}+\beta_{15}\right) \\
-\left(\beta_{3}+\beta_{14}\right)=-2.2599\end{array}$ \\
\hline$(1 / 0)$ & $\begin{array}{l}H_{0}: \beta_{1}+\beta_{12}=0 \\
\text { p-value }=0.0142 \\
\beta_{1}+\beta_{12}=-1.9053\end{array}$ & $\begin{array}{l}H_{0}: \beta_{1}+\beta_{7}+\beta_{13}=0 \\
\text { p-value }=0.0000 \\
\beta_{1}+\beta_{7}+\beta_{13}=-1.7168\end{array}$ \\
\hline$(1 / 1)$ & $\begin{array}{l}H_{0}: \beta_{3}+\beta_{8}=\beta_{1}+\beta_{4}+\beta_{10}+\beta_{12} \\
\text { p-value }=0.0005 \\
\left(\beta_{1}+\beta_{4}+\beta_{10}+\beta_{12}\right)-\left(\beta_{3}+\beta_{8}\right)=-1.0934\end{array}$ & $\begin{array}{l}H_{0}: \beta_{3}+\beta_{9}+\beta_{14} \\
=\beta_{1}+\beta_{4}+\beta_{7}+\beta_{11}+\beta_{13}+\beta_{15} \\
\text { p-value }=0.0000 \\
\left(\beta_{1}+\beta_{4}+\beta_{7}+\beta_{11}+\beta_{13}+\beta_{15}\right) \\
-\left(\beta_{3}+\beta_{9}+\beta_{14}\right)=-1.2509\end{array}$ \\
\hline
\end{tabular}

Note: $q_{t}=1$ if expectations are positive, $x_{t}=1$ if unemployed in $t$

Table 9: Expected versus unexpected unemployment - all indivduals

\begin{tabular}{|c|c|}
\hline$\left(q_{\left.t-1 / q_{t}\right)}\left(x_{t-1} / x_{t}\right)\right.$ & $(0 / 1)$ \\
\hline$(0 / 0)$ vs $(1 / 0)$ & $\begin{array}{l}H_{0}: \beta_{5}+\beta_{12}=0 \\
\text { p-value }=0.0575 \\
\left(\beta_{5}+\beta_{12}\right)=-1.5379\end{array}$ \\
\hline$(0 / 1)$ vs $(1 / 1)$ & $\begin{array}{l}H_{0}: \beta_{5}+\beta_{10}+\beta_{12}=0 \\
\text { p-value }=0.9008 \\
\left(\beta_{5}+\beta_{10}+\beta_{12}\right)=-0.0419\end{array}$ \\
\hline
\end{tabular}

Note: $q_{t}=1$ if expectations are positive, $x_{t}=1$ if unemployed in $t$ 
Table 10: Fixed effects estimates for life satisfaction - by gender

\begin{tabular}{|c|c|c|c|c|c|}
\hline \multirow[b]{2}{*}{ Variable } & & \multicolumn{2}{|c|}{ Male } & \multicolumn{2}{|c|}{ Female } \\
\hline & & Coefficient & HAC SE & Coefficient & HAC SE \\
\hline$x_{i s t}$ & $\beta_{1}$ & -0.1930 & 0.3101 & $-0.5517^{*}$ & 0.3116 \\
\hline$x_{i s t-1}$ & $\beta_{2}$ & -0.0874 & 0.1951 & -0.1488 & 0.1895 \\
\hline $\bar{q}_{i s t}$ & $\beta_{3}$ & $0.2008^{* * *}$ & 0.0259 & $0.2332^{* * *}$ & 0.0296 \\
\hline$\underline{q}_{i s t}$ & $\beta_{4}$ & $-0.8133^{* *}$ & 0.3451 & 0.1529 & 0.3543 \\
\hline $\bar{q}_{i s t-1}$ & $\beta_{5}$ & $0.0541^{* *}$ & 0.0240 & $0.0755^{* *}$ & 0.0306 \\
\hline$\underline{q}_{i s t-1}$ & $\beta_{6}$ & -0.0079 & 0.2042 & 0.0880 & 0.2070 \\
\hline$x_{i s t} \times x_{i s t-1}$ & $\beta_{7}$ & $-1.0904^{*}$ & 0.6440 & 0.0749 & 0.9737 \\
\hline $\bar{q}_{i s t} \times \bar{q}_{i s t-1}$ & $\beta_{8}$ & 0.0130 & 0.0339 & -0.0615 & 0.0419 \\
\hline $\bar{q}_{i s t} \times \underline{q}_{i s t-1}$ & $\beta_{9}$ & $-1.3243^{* * *}$ & 0.4752 & -0.1012 & 0.5319 \\
\hline$\underline{q}_{i s t} \times \bar{q}_{i s t-1}$ & $\beta_{10}$ & 1.4514 & 1.1996 & $1.9160^{* *}$ & 0.8826 \\
\hline$\underline{q}_{i s t} \times \underline{q}_{i s t-1}$ & $\beta_{11}$ & 1.0028 & 0.9886 & 1.6252 & 1.2343 \\
\hline $\bar{q}_{i s t-1} \times x_{i s t}$ & $\beta_{12}$ & -1.3649 & 1.1375 & $-2.1862^{* * *}$ & 0.7146 \\
\hline$\underline{q}_{i s t-1} \times x_{i s t}$ & $\beta_{13}$ & -0.4965 & 0.7184 & -1.2393 & 1.0928 \\
\hline $\bar{q}_{i s t} \times x_{i s t-1}$ & $\beta_{14}$ & $1.1417^{* *}$ & 0.4468 & 0.3780 & 0.5049 \\
\hline$\underline{q}_{i s t} \times x_{i s t-1}$ & $\beta_{15}$ & 0.7222 & 0.8475 & -1.4823 & 0.9835 \\
\hline Age & & $-0.0365^{* *}$ & 0.0179 & -0.0247 & 0.0216 \\
\hline Years of Education & & -0.0185 & 0.0218 & -0.0190 & 0.0289 \\
\hline Married & & $0.1350^{* * *}$ & 0.0440 & $0.1056^{*}$ & 0.0610 \\
\hline Children in household & & 0.0255 & 0.0168 & 0.0000 & 0.0251 \\
\hline Net Income & & $0.0001^{* * *}$ & 0.0000 & $0.0001^{* *}$ & 0.0000 \\
\hline Foreign & & -0.1410 & 0.1461 & -0.2112 & 0.2319 \\
\hline Private insurance & & 0.0543 & 0.0524 & 0.0087 & 0.0930 \\
\hline Blue collar & & -0.0537 & 0.0387 & -0.0136 & 0.0516 \\
\hline Self assessed health & & $0.4600^{* * *}$ & 0.0144 & $0.4530^{* * *}$ & 0.0160 \\
\hline Constant & & $6.7223^{* * *}$ & 0.8834 & $6.4740^{* * *}$ & 1.0288 \\
\hline$\alpha_{i}$ & & yes & & yes & \\
\hline$\delta_{s}$ & & yes & & yes & \\
\hline$\lambda_{t}$ & & yes & & yes & \\
\hline$\left(\delta_{s}\right)\left(\lambda_{t}\right)$ & & yes & & yes & \\
\hline$N$ & & 34608 & & 27527 & \\
\hline
\end{tabular}

Note: ${ }^{*} \mathrm{p}<0.1,{ }^{* *} \mathrm{p}<0.05,{ }^{* * *} \mathrm{p}<0.01$ 
Table 11: Employed versus unemployed - male

\begin{tabular}{|c|c|c|}
\hline$\left(q_{t-1} / q_{t}\right)-\left(x_{t-1} / x_{t}\right)$ & $(0 / 0)$ vs $(0 / 1)$ & $(1 / 0)$ vs $(1 / 1)$ \\
\hline$(0 / 0)$ & $\begin{array}{l}H_{0}: \beta_{1}=0 \\
\text { p-value }=0.5337 \\
\beta_{1}=-0.1930\end{array}$ & $\begin{array}{l}H_{0}: \beta_{1}+\beta_{7}=0 \\
\text { p-value }=0.0192 \\
\beta_{1}+\beta_{7}=-1.2834\end{array}$ \\
\hline$(0 / 1)$ & $\begin{array}{l}H_{0}: \beta_{3}=\beta_{1}+\beta_{4} \\
\text { p-value }=0.0000 \\
\left(\beta_{1}+\beta_{4}\right)-\left(\beta_{3}\right)=-1.2070\end{array}$ & $\begin{array}{l}H_{0}: \beta_{3}+\beta_{14} \\
=\beta_{1}+\beta_{4}+\beta_{7}+\beta_{15} \\
\text { p-value }=0.0023 \\
\left(\beta_{1}+\beta_{4}+\beta_{7}+\beta_{15}\right) \\
-\left(\beta_{3}+\beta_{14}\right)=-2.7169\end{array}$ \\
\hline$(1 / 0)$ & $\begin{array}{l}H_{0}: \beta_{1}+\beta_{12}=0 \\
\text { p-value }=0.1544 \\
\beta_{1}+\beta_{12}=-1.5579\end{array}$ & $\begin{array}{l}H_{0}: \beta_{1}+\beta_{7}+\beta_{13}=0 \\
\text { p-value }=0.0002 \\
\beta_{1}+\beta_{7}+\beta_{13}=-1.7800\end{array}$ \\
\hline$(1 / 1)$ & $\begin{array}{l}H_{0}: \beta_{3}+\beta_{8}=\beta_{1}+\beta_{4}+\beta_{10}+\beta_{12} \\
\text { p-value }=0.0014 \\
\left(\beta_{1}+\beta_{4}+\beta_{10}+\beta_{12}\right)-\left(\beta_{3}+\beta_{8}\right)=-1.1335\end{array}$ & $\begin{array}{l}H_{0}: \beta_{3}+\beta_{9}+\beta_{14} \\
=\beta_{1}+\beta_{4}+\beta_{7}+\beta_{11}+\beta_{13}+\beta_{15} \\
\text { p-value }=0.0020 \\
\left(\beta_{1}+\beta_{4}+\beta_{7}+\beta_{11}+\beta_{13}+\beta_{15}\right) \\
-\left(\beta_{3}+\beta_{9}+\beta_{14}\right)=-0.8862\end{array}$ \\
\hline
\end{tabular}

Note: $q_{t}=1$ if expectations are positive, $x_{t}=1$ if unemployed in $t$

Table 12: Employed versus unemployed - female

\begin{tabular}{|c|c|c|}
\hline$\left(q_{t-1} / q_{t}\right)$ & $(0 / 0)$ vs $(0 / 1)$ & $(1 / 0)$ vs $(1 / 1)$ \\
\hline$(0 / 0)$ & $\begin{array}{l}H_{0}: \beta_{1}=0 \\
\text { p-value }=0.0767 \\
\beta_{1}=-0.5517\end{array}$ & $\begin{array}{l}H_{0}: \beta_{1}+\beta_{7}=0 \\
\text { p-value }=0.6326 \\
\beta_{1}+\beta_{7}=-0.4768\end{array}$ \\
\hline$(0 / 1)$ & $\begin{array}{l}H_{0}: \beta_{3}=\beta_{1}+\beta_{4} \\
\text { p-value }=0.0009 \\
\left(\beta_{1}+\beta_{4}\right)-\left(\beta_{3}\right)=-0.6321\end{array}$ & $\begin{array}{l}H_{0}: \beta_{3}+\beta_{14} \\
=\beta_{1}+\beta_{4}+\beta_{7}+\beta_{15} \\
\text { p-value }=0.0041 \\
\left(\beta_{1}+\beta_{4}+\beta_{7}+\beta_{15}\right) \\
-\left(\beta_{3}+\beta_{14}\right)=-2.4174\end{array}$ \\
\hline$(1 / 0)$ & $\begin{array}{l}H_{0}: \beta_{1}+\beta_{12}=0 \\
\text { p-value }=0.0000 \\
\beta_{1}+\beta_{12}=-2.7379\end{array}$ & $\begin{array}{l}H_{0}: \beta_{1}+\beta_{7}+\beta_{13}=0 \\
\text { p-value }=0.0003 \\
\beta_{1}+\beta_{7}+\beta_{13}=-1.7161\end{array}$ \\
\hline$(1 / 1)$ & $\begin{array}{l}H_{0}: \beta_{3}+\beta_{8}=\beta_{1}+\beta_{4}+\beta_{10}+\beta_{12} \\
\text { p-value }=0.0870 \\
\left(\beta_{1}+\beta_{4}+\beta_{10}+\beta_{12}\right)-\left(\beta_{3}+\beta_{8}\right)=-0.8410\end{array}$ & $\begin{array}{l}H_{0}: \beta_{3}+\beta_{9}+\beta_{14} \\
=\beta_{1}+\beta_{4}+\beta_{7}+\beta_{11}+\beta_{13}+\beta_{15} \\
\text { p-value }=0.0003 \\
\left(\beta_{1}+\beta_{4}+\beta_{7}+\beta_{11}+\beta_{13}+\beta_{15}\right) \\
-\left(\beta_{3}+\beta_{9}+\beta_{14}\right)=-1.9303\end{array}$ \\
\hline
\end{tabular}

Note: $q_{t}=1$ if expectations are positive, $x_{t}=1$ if unemployed in $t$ 
Table 13: Expected versus unexpected unemployment - male

\begin{tabular}{|c|c|}
\hline$\left(q_{t-1} / q_{t}\right)$ & $(0 / 1)$ \\
\hline$(0 / 0)$ vs $(1 / 0)$ & $\begin{array}{l}H_{0}: \beta_{5}+\beta_{12}=0 \\
\text { p-value }=0.2490 \\
\left(\beta_{5}+\beta_{12}\right)=-1.3108\end{array}$ \\
\hline$(0 / 1)$ vs $(1 / 1)$ & $\begin{array}{l}H_{0}: \beta_{5}+\beta_{10}+\beta_{12}=0 \\
\text { p-value }=0.7138 \\
\left(\beta_{5}+\beta_{10}+\beta_{12}\right)=0.1406\end{array}$ \\
\hline
\end{tabular}

Note: $q_{t}=1$ if expectations are positive, $x_{t}=1$ if unemployed in $t$

Table 14: Expected versus unexpected unemployment - female

\begin{tabular}{|c|c|}
\hline $\mathrm{P}_{\left(q_{t-1} / q_{t}\right)}\left(x_{t-1} / x_{t}\right)$ & $(0 / 1)$ \\
\hline$(0 / 0)$ vs $(1 / 0)$ & $\begin{array}{l}H_{0}: \beta_{5}+\beta_{12}=0 \\
\text { p-value }=0.0031 \\
\left(\beta_{5}+\beta_{12}\right)=-2.1107\end{array}$ \\
\hline$(0 / 1)$ vs $(1 / 1)$ & $\begin{array}{l}H_{0}: \beta_{5}+\beta_{10}+\beta_{12}=0 \\
\text { p-value }=0.7083 \\
\left(\beta_{5}+\beta_{10}+\beta_{12}\right)=-0.1947\end{array}$ \\
\hline
\end{tabular}

Note: $q_{t}=1$ if expectations are positive, $x_{t}=1$ if unemployed in $t$ 
Table 15: Fixed effects estimates for life satisfaction - by age

\begin{tabular}{|c|c|c|c|c|c|}
\hline \multirow[b]{2}{*}{ Variable } & & \multicolumn{2}{|c|}{$30-40$} & \multicolumn{2}{|c|}{$41-55$} \\
\hline & & Coefficient & HAC SE & Coefficient & HAC SE \\
\hline$x_{i s t}$ & $\beta_{1}$ & $-0.9223^{*}$ & 0.5290 & -0.2328 & 0.2476 \\
\hline$x_{i s t-1}$ & $\beta_{2}$ & $-0.8241 * * *$ & 0.2829 & 0.1703 & 0.1578 \\
\hline $\bar{q}_{i s t}$ & $\beta_{3}$ & $0.2397^{* * *}$ & 0.0310 & $0.2118^{* * *}$ & 0.0257 \\
\hline$\underline{q}_{i s t}$ & $\beta_{4}$ & -0.0409 & 0.5864 & -0.4071 & 0.2838 \\
\hline $\bar{q}_{i s t-1}$ & $\beta_{5}$ & $0.0983^{* * *}$ & 0.0298 & $0.0556^{* *}$ & 0.0259 \\
\hline$\underline{q}_{i s t-1}$ & $\beta_{6}$ & $0.8115^{* * *}$ & 0.2905 & -0.2497 & 0.1747 \\
\hline$x_{i s t} \times x_{i s t-1}$ & $\beta_{7}$ & -0.8023 & 1.4722 & -0.3582 & 0.5604 \\
\hline $\bar{q}_{i s t} \times \bar{q}_{i s t-1}$ & $\beta_{8}$ & $-0.0961^{* *}$ & 0.0408 & 0.0115 & 0.0361 \\
\hline $\bar{q}_{i s t} \times \underline{q}_{i s t-1}$ & $\beta_{9}$ & $-2.0815^{* * *}$ & 0.7744 & 0.0005 & 0.4393 \\
\hline$\underline{q}_{i s t} \times \bar{q}_{i s t-1}$ & $\beta_{10}$ & $2.3309^{* * *}$ & 0.8276 & 0.6217 & 1.1881 \\
\hline$\underline{q}_{i s t} \times \underline{q}_{i s t-1}$ & $\beta_{11}$ & 0.8471 & 1.5446 & 1.0205 & 0.9507 \\
\hline $\bar{q}_{i s t-1} \times x_{i s t}$ & $\beta_{12}$ & $-1.9170^{* * *}$ & 0.7040 & -1.1909 & 1.0895 \\
\hline$\underline{q}_{i s t-1} \times x_{i s t}$ & $\beta_{13}$ & -0.0606 & 1.1869 & $-1.2872^{*}$ & 0.6900 \\
\hline $\bar{q}_{i s t} \times x_{i s t-1}$ & $\beta_{14}$ & $1.9672^{* * *}$ & 0.7555 & 0.1033 & 0.3981 \\
\hline$\underline{q}_{i s t} \times x_{i s t-1}$ & $\beta_{15}$ & 0.1054 & 1.6763 & 0.1925 & 0.8119 \\
\hline Age & & $-0.0467^{*}$ & 0.0278 & -0.0147 & 0.0169 \\
\hline Years of Education & & 0.0003 & 0.0236 & -0.0183 & 0.0280 \\
\hline Married & & $0.2077^{* * *}$ & 0.0449 & 0.0406 & 0.0659 \\
\hline Children in household & & 0.0263 & 0.0239 & 0.0277 & 0.0209 \\
\hline Net Income & & $0.0001^{* * *}$ & 0.0000 & $0.0001^{* * *}$ & 0.0000 \\
\hline Foreign & & -0.0952 & 0.1671 & -0.2523 & 0.2067 \\
\hline Private insurance & & -0.0752 & 0.0653 & $0.1354^{*}$ & 0.0698 \\
\hline Blue collar & & $-0.0774^{*}$ & 0.0469 & 0.0095 & 0.0425 \\
\hline Self assessed health & & $0.4119^{* * *}$ & 0.0178 & $0.4640^{* * *}$ & 0.0136 \\
\hline Constant & & $6.7249^{* * *}$ & 1.0561 & $5.9936^{* * *}$ & 0.9546 \\
\hline$\alpha_{i}$ & & yes & & yes & \\
\hline$\delta_{s}$ & & yes & & yes & \\
\hline$\lambda_{t}$ & & yes & & yes & \\
\hline$\left(\delta_{s}\right)\left(\lambda_{t}\right)$ & & yes & & yes & \\
\hline$N$ & & 24731 & & 37404 & \\
\hline
\end{tabular}

Note: ${ }^{*} \mathrm{p}<0.1,{ }^{* *} \mathrm{p}<0.05,{ }^{* * *} \mathrm{p}<0.01$ 
Table 16: Employed versus unemployed - 30 - 40

\begin{tabular}{|c|c|c|}
\hline$\left(q_{t-1} / q_{t}\right)$ & $(0 / 0)$ vs $(0 / 1)$ & $(1 / 0)$ vs $(1 / 1)$ \\
\hline$(0 / 0)$ & $\begin{array}{l}H_{0}: \beta_{1}=0 \\
\text { p-value }=0.0813 \\
\beta_{1}=-0.9223\end{array}$ & $\begin{array}{l}H_{0}: \beta_{1}+\beta_{7}=0 \\
\text { p-value }=0.1677 \\
\beta_{1}+\beta_{7}=-1.7246\end{array}$ \\
\hline$(0 / 1)$ & $\begin{array}{l}H_{0}: \beta_{3}=\beta_{1}+\beta_{4} \\
\text { p-value }=0.0000 \\
\left(\beta_{1}+\beta_{4}\right)-\left(\beta_{3}\right)=-1.2028\end{array}$ & $\begin{array}{l}H_{0}: \beta_{3}+\beta_{14} \\
=\beta_{1}+\beta_{4}+\beta_{7}+\beta_{15} \\
\text { p-value }=0.0022 \\
\left(\beta_{1}+\beta_{4}+\beta_{7}+\beta_{15}\right) \\
-\left(\beta_{3}+\beta_{14}\right)=-3.8670\end{array}$ \\
\hline$(1 / 0)$ & $\begin{array}{l}H_{0}: \beta_{1}+\beta_{12}=0 \\
\text { p-value }=0.0000 \\
\beta_{1}+\beta_{12}=-2.8392\end{array}$ & $\begin{array}{l}H_{0}: \beta_{1}+\beta_{7}+\beta_{13}=0 \\
\text { p-value }=0.0000 \\
\beta_{1}+\beta_{7}+\beta_{13}=-1.7852\end{array}$ \\
\hline$(1 / 1)$ & $\begin{array}{l}H_{0}: \beta_{3}+\beta_{8}=\beta_{1}+\beta_{4}+\beta_{10}+\beta_{12} \\
\text { p-value }=0.0584 \\
\left(\beta_{1}+\beta_{4}+\beta_{10}+\beta_{12}\right)-\left(\beta_{3}+\beta_{8}\right)=-0.6928\end{array}$ & $\begin{array}{l}H_{0}: \beta_{3}+\beta_{9}+\beta_{14} \\
=\beta_{1}+\beta_{4}+\beta_{7}+\beta_{11}+\beta_{13}+\beta_{15} \\
\text { p-value }=0.0059 \\
\left(\beta_{1}+\beta_{4}+\beta_{7}+\beta_{11}+\beta_{13}+\beta_{15}\right) \\
-\left(\beta_{3}+\beta_{9}+\beta_{14}\right)=-0.9989\end{array}$ \\
\hline
\end{tabular}

Note: $q_{t}=1$ if expectations are positive, $x_{t}=1$ if unemployed in $t$

Table 17: Employed versus unemployed - 41 - 55

\begin{tabular}{|c|c|c|}
\hline$\left(q_{t-1} / q_{t}\right) \quad\left(x_{t-1} / x_{t}\right)$ & $(0 / 0)$ vs $(0 / 1)$ & $(1 / 0)$ vs $(1 / 1)$ \\
\hline$(0 / 0)$ & $\begin{array}{l}H_{0}: \beta_{1}=0 \\
\text { p-value }=0.3472 \\
\beta_{1}=-0.2328\end{array}$ & $\begin{array}{l}H_{0}: \beta_{1}+\beta_{7}=0 \\
\text { p-value }=0.2494 \\
\beta_{1}+\beta_{7}=-0.5910\end{array}$ \\
\hline$(0 / 1)$ & $\begin{array}{l}H_{0}: \beta_{3}=\beta_{1}+\beta_{4} \\
\text { p-value }=0.0000 \\
\left(\beta_{1}+\beta_{4}\right)-\left(\beta_{3}\right)=-0.8517\end{array}$ & $\begin{array}{l}H_{0}: \beta_{3}+\beta_{14} \\
=\beta_{1}+\beta_{4}+\beta_{7}+\beta_{15} \\
\text { p-value }=0.2085 \\
\left(\beta_{1}+\beta_{4}+\beta_{7}+\beta_{15}\right) \\
-\left(\beta_{3}+\beta_{14}\right)=-1.1207\end{array}$ \\
\hline$(1 / 0)$ & $\begin{array}{l}H_{0}: \beta_{1}+\beta_{12}=0 \\
\text { p-value }=0.1787 \\
\beta_{1}+\beta_{12}=-1.4238\end{array}$ & $\begin{array}{l}H_{0}: \beta_{1}+\beta_{7}+\beta_{13}=0 \\
\text { p-value }=0.0000 \\
\beta_{1}+\beta_{7}+\beta_{13}=-1.8782\end{array}$ \\
\hline$(1 / 1)$ & $\begin{array}{l}H_{0}: \beta_{3}+\beta_{8}=\beta_{1}+\beta_{4}+\beta_{10}+\beta_{12} \\
\text { p-value }=0.0019 \\
\left(\beta_{1}+\beta_{4}+\beta_{10}+\beta_{12}\right)-\left(\beta_{3}+\beta_{8}\right)=-1.4324\end{array}$ & $\begin{array}{l}H_{0}: \beta_{3}+\beta_{9}+\beta_{14} \\
=\beta_{1}+\beta_{4}+\beta_{7}+\beta_{11}+\beta_{13}+\beta_{15} \\
\text { p-value }=0.0000 \\
\left(\beta_{1}+\beta_{4}+\beta_{7}+\beta_{11}+\beta_{13}+\beta_{15}\right) \\
-\left(\beta_{3}+\beta_{9}+\beta_{14}\right)=-1.3879\end{array}$ \\
\hline
\end{tabular}

Note: $q_{t}=1$ if expectations are positive, $x_{t}=1$ if unemployed in $t$ 
Table 18: Expected versus unexpected unemployment - 30 - 40

\begin{tabular}{|c|c|}
\hline $\mathrm{P}_{\left(q_{t-1} / q_{t}\right)}\left(x_{t-1} / x_{t}\right)$ & $(0 / 1)$ \\
\hline$(0 / 0)$ vs $(1 / 0)$ & $\begin{array}{l}H_{0}: \beta_{5}+\beta_{12}=0 \\
\text { p-value }=0.0098 \\
\left(\beta_{5}+\beta_{12}\right)=-1.8187\end{array}$ \\
\hline$(0 / 1)$ vs $(1 / 1)$ & $\begin{array}{l}H_{0}: \beta_{5}+\beta_{10}+\beta_{12}=0 \\
\text { p-value }=0.2477 \\
\left(\beta_{5}+\beta_{10}+\beta_{12}\right)=0.5123\end{array}$ \\
\hline
\end{tabular}

Note: $q_{t}=1$ if expectations are positive, $x_{t}=1$ if unemployed in $t$

Table 19: Expected versus unexpected unemployment - 41 - 55

\begin{tabular}{|c|c|}
\hline $\mathrm{P}_{\left(q_{t-1} / q_{t}\right)}\left(x_{t-1} / x_{t}\right)$ & $(0 / 1)$ \\
\hline$(0 / 0)$ vs $(1 / 0)$ & $\begin{array}{l}H_{0}: \beta_{5}+\beta_{12}=0 \\
\text { p-value }=0.2972 \\
\left(\beta_{5}+\beta_{12}\right)=-1.1354\end{array}$ \\
\hline$(0 / 1)$ vs $(1 / 1)$ & $\begin{array}{l}H_{0}: \beta_{5}+\beta_{10}+\beta_{12}=0 \\
\text { p-value }=0.2820 \\
\left(\beta_{5}+\beta_{10}+\beta_{12}\right)=-0.5137\end{array}$ \\
\hline
\end{tabular}

Note: $q_{t}=1$ if expectations are positive, $x_{t}=1$ if unemployed in $t$ 
Table 20: Interpretation of coefficients

\begin{tabular}{|c|c|c|c|c|c|}
\hline & \multicolumn{3}{|c|}{$q_{i t-1}$} & \multicolumn{2}{|r|}{1} \\
\hline$x_{i t-1}$ & $x_{i t}$ & 0 & 1 & 0 & 1 \\
\hline & 0 & $\beta_{0} \quad(0000)$ & $\beta_{0}+\beta_{3}$ & $\beta_{0}+\beta_{5}$ & $\beta_{0}+\beta_{3}+\beta_{5}+\beta_{8}$ \\
\hline 0 & 1 & $\beta_{0}+\beta_{1}^{(0100)}$ & $\beta_{0}+\beta_{1}+\beta_{4}$ & $\beta_{0}+\beta_{1}+\beta_{5}+\beta_{12}$ & $\begin{array}{l}\beta_{0}+\beta_{1}+\beta_{4}+\beta_{5} \\
+\beta_{10}+\beta_{12}\end{array}$ \\
\hline 7 & 0 & $\beta_{0}+\beta_{2}^{(1000)}$ & $\beta_{0}+\beta_{2}+\beta_{3}+\beta_{14}^{(1001)}$ & $\beta_{0}+\beta_{2}+\beta_{6}$ & $\begin{array}{c}\beta_{0}+\beta_{2}+\beta_{3}+\beta_{6}+\beta_{9} \\
+\beta_{14}\end{array}$ \\
\hline 1 & 1 & $\beta_{0}+\beta_{1}+\beta_{2}+\beta_{7}$ & $\begin{array}{c}\beta_{0}+\beta_{1}+\beta_{2}+\beta_{4}+\beta_{7} \\
+\beta_{15}\end{array}$ & $\begin{array}{c}\beta_{0}+\beta_{1}+\beta_{2}+\beta_{6}+\beta_{7} \\
+\beta_{13}\end{array}$ & $\begin{array}{c}\beta_{0}+\beta_{1}+\beta_{2}+\beta_{4}+\beta_{6}+\beta_{7} \\
+\beta_{11}+\beta_{13}+\beta_{15}\end{array}$ \\
\hline
\end{tabular}

Note: $q_{i t}=1$ if expectations are positive, $x_{i t}=1$ if unemployed in $t$ 
Table 21: Summary statistics for life satisfaction and expectations by employment status and age

\begin{tabular}{|c|c|c|c|c|c|c|c|}
\hline \multirow[b]{2}{*}{ Age } & \multirow[b]{2}{*}{ Variable } & \multicolumn{3}{|c|}{$x_{i t}=0$} & \multicolumn{3}{|c|}{$x_{i t}=1$} \\
\hline & & Mean & SD & $\mathrm{N}$ & Mean & SD & $\mathrm{N}$ \\
\hline \multirow{2}{*}{30} & $y$ & 7.255 & 1.523 & \multirow{2}{*}{1662} & 5.824 & 2.430 & \multirow{2}{*}{17} \\
\hline & $\bar{q} / \underline{q}$ & 0.425 & 0.495 & & 0.882 & 0.332 & \\
\hline \multirow{2}{*}{31} & $y$ & 7.276 & 1.488 & \multirow{2}{*}{1729} & 5.222 & 2.108 & \multirow{2}{*}{9} \\
\hline & $\bar{q} / \underline{q}$ & 0.426 & 0.495 & & 0.778 & 0.441 & \\
\hline \multirow{2}{*}{32} & $y$ & 7.229 & 1.536 & \multirow{2}{*}{1871} & 6.524 & 2.205 & \multirow{2}{*}{21} \\
\hline & $\bar{q} / \underline{q}$ & 0.433 & 0.496 & & 0.905 & 0.301 & \\
\hline \multirow{2}{*}{33} & $y$ & 7.198 & 1.527 & \multirow{2}{*}{2022} & 6.111 & 1.779 & \multirow{2}{*}{18} \\
\hline & $\bar{q} / \underline{q}$ & 0.409 & 0.492 & & 0.944 & 0.236 & \\
\hline \multirow{2}{*}{34} & $y$ & 7.209 & 1.500 & \multirow{2}{*}{2140} & 5.050 & 1.820 & \\
\hline & $\bar{q} / q$ & 0.422 & 0.494 & & 0.800 & 0.410 & \\
\hline 35 & $y$ & 7.192 & 1.515 & 2275 & 5.583 & 1.311 & 11 \\
\hline 50 & $\bar{q} / \underline{q}$ & 0.411 & 0.492 & 2210 & 0.667 & 0.492 & 11 \\
\hline 36 & $y$ & 7.157 & 1.526 & 2404 & 5.294 & 2.085 & 17 \\
\hline 0 & $\bar{q} / \underline{q}$ & 0.395 & 0.489 & 2404 & 0.941 & 0.243 & 10 \\
\hline 37 & $y$ & 7.124 & 1.558 & 2464 & 5.867 & 1.767 & 15 \\
\hline & $\bar{q} / \underline{q}$ & 0.395 & 0.489 & 2707 & 0.933 & 0.258 & \\
\hline 38 & $y$ & 7.060 & 1.574 & 2583 & 5.889 & 1.530 & 17 \\
\hline 0 & $\bar{q} / \underline{q}$ & 0.391 & 0.488 & 2000 & 0.611 & 0.502 & 1 \\
\hline 39 & $y$ & 7.124 & 1.560 & 2672 & 5.125 & 1.893 & 16 \\
\hline & $\bar{q} / \underline{q}$ & 0.397 & 0.489 & 2012 & 0.813 & 0.403 & \\
\hline 40 & $y$ & 7.095 & 1.563 & 2728 & 5.611 & 3.183 & 18 \\
\hline 40 & $\bar{q} / \underline{q}$ & 0.391 & 0.488 & 2120 & 0.833 & 0.383 & 10 \\
\hline 4 & $y$ & 7.027 & 1.565 & 0785 & 5.500 & 1.713 & 16 \\
\hline 71 & $\bar{q} / \underline{q}$ & 0.386 & 0.487 & 2100 & 0.875 & 0.342 & 10 \\
\hline 42 & $y$ & 7.048 & 1.563 & 2836 & 5.692 & 2.175 & 3 \\
\hline & $\bar{q} / \underline{q}$ & 0.384 & 0.486 & & 0.769 & 0.439 & \\
\hline 43 & $y$ & 6.960 & 1.620 & 2787 & 5.000 & 1.440 & 25 \\
\hline & $\bar{q} / \underline{q}$ & 0.375 & 0.484 & & 0.750 & 0.441 & \\
\hline 44 & $y$ & 6.970 & 1.629 & 2702 & 5.462 & 1.964 & 4 \\
\hline & $\bar{q} / \underline{q}$ & 0.371 & 0.483 & & 0.731 & 0.452 & \\
\hline 45 & $y$ & 6.961 & 1.609 & 2727 & 4.762 & 1.921 & 21 \\
\hline To & $\bar{q} / \underline{q}$ & 0.371 & 0.483 & 2121 & 0.762 & 0.436 & \\
\hline 46 & $y$ & 6.971 & 1.617 & 2630 & 5.294 & 1.993 & 6 \\
\hline 40 & $\bar{q} / \underline{q}$ & 0.390 & 0.488 & 2000 & 0.765 & 0.437 & 10 \\
\hline 47 & $y$ & 6.965 & 1.662 & 2595 & 5.360 & 2.378 & 23 \\
\hline & $\bar{q} / \underline{q}$ & 0.378 & 0.485 & & 0.600 & 0.500 & \\
\hline 48 & $y$ & 6.953 & 1.681 & 2568 & 5.261 & 2.220 & 23 \\
\hline & $\bar{q} / \underline{q}$ & 0.385 & 0.487 & & 0.783 & 0.422 & \\
\hline 40 & $y$ & 7.010 & 1.624 & 2487 & 5.053 & 2.041 & 9 \\
\hline & $\bar{q} / \underline{q}$ & 0.403 & 0.491 & 2401 & 0.895 & 0.315 & \\
\hline 50 & $y$ & 6.995 & 1.637 & 2416 & 5.217 & 1.882 & 21 \\
\hline & $\bar{q} / \underline{q}$ & 0.404 & 0.491 & & 0.609 & 0.499 & \\
\hline 51 & $y$ & 6.998 & 1.655 & 2204 & 4.895 & 1.792 & 18 \\
\hline 01 & $\bar{q} / \underline{q}$ & 0.402 & 0.490 & & 0.684 & 0.478 & 10 \\
\hline 52 & $y$ & 6.994 & 1.623 & 8207 & 5.526 & 1.806 & 10 \\
\hline 52 & $\bar{q} / \underline{q}$ & 0.431 & 0.495 & 2221 & 0.684 & 0.478 & 19 \\
\hline 53 & $y$ & 7.033 & 1.625 & 2127 & 5.500 & 1.900 & 10 \\
\hline & $\bar{q} / \underline{q}$ & 0.455 & 0.498 & & 0.500 & 0.527 & \\
\hline 54 & $y$ & 7.016 & 1.620 & 1989 & 6.400 & 1.776 & 10 \\
\hline 84 & $\bar{q} / \underline{q}$ & 0.454 & 0.498 & 1909 & 0.700 & 0.483 & 10 \\
\hline 55 & $y$ & 6.972 & 1.646 & 1838 & 6.143 & 1.864 & \\
\hline & $\bar{q} / \underline{q}$ & 0.477 & 0.500 & & 0.429 & 0.535 & \\
\hline
\end{tabular}

$y$ : life satisfaction $(0=$ low, $10=$ high $)$

$\bar{q}$ : share of employed with positive expectation

$\underline{q}$ : share of unemployed with positive expectations 
Table 22: Counts of correctly predicted unemployment - by age

\begin{tabular}{|l|rr|rr|}
\hline & \multicolumn{2}{|c|}{$30-40$} & \multicolumn{2}{|c|}{$41-55$} \\
& $x_{i t}=0$ & $x_{i t}=1$ & $x_{i t}=0$ & $x_{i t}=1$ \\
\hline $\bar{q}_{i t-1}=1$ & 10086 & 22 & 14886 & 10 \\
$\bar{q}_{i t-1}=0$ & 13796 & 93 & 21490 & 180 \\
\hline Total & 23882 & 115 & 36376 & 190 \\
\hline \hline$\underline{q}_{i t-1}=1$ & 585 & 50 & 585 & 60 \\
$\underline{q}_{i t-1}=0$ & 83 & 16 & 167 & 26 \\
\hline Total & 668 & 66 & 752 & 86 \\
\hline
\end{tabular}

$\bar{q}$ : expectations of the employed

$\underline{q}$ : expectations of the unemployed

Table 23: Counts of unemployment periods - by age groups

\begin{tabular}{|c|rr|rr|}
\hline Counts & \multicolumn{2}{|c|}{$30-40$} & \multicolumn{2}{|c|}{$41-55$} \\
$\sum_{t=1}^{T} x_{i t}$ & Number & Percent & Number & Percent \\
\hline 0 & 24081 & 97.37 & 36372 & 97.24 \\
1 & 517 & 2.09 & 802 & 2.14 \\
2 & 107 & 0.43 & 175 & 0.47 \\
3 & 20 & 0.08 & 48 & 0.13 \\
4 & 6 & 0.02 & 7 & 0.02 \\
\hline Total & 24731 & 100.00 & 37404 & 100.00 \\
\hline
\end{tabular}

